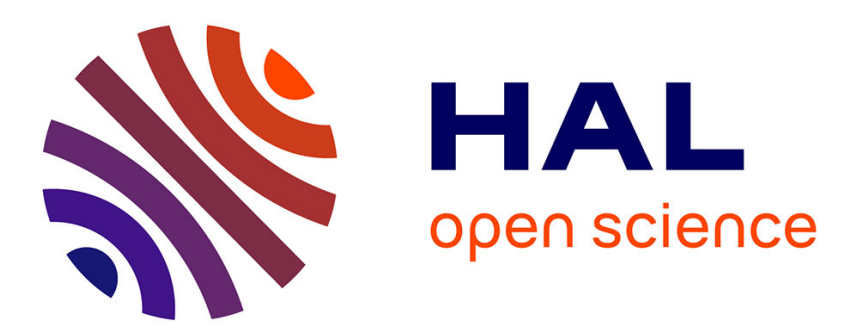

\title{
Transient climate change scenario simulation of the Mediterranean Sea for the 21st century using a high-resolution ocean circulation model
}

Samuel Somot, Florence Sevault, Michel Déqué

\section{- To cite this version:}

Samuel Somot, Florence Sevault, Michel Déqué. Transient climate change scenario simulation of the Mediterranean Sea for the 21st century using a high-resolution ocean circulation model. Climate Dynamics, 2006, 27 (7-8), pp.851-879. 10.1007/s00382-006-0167-z . hal-00195045

\section{HAL Id: hal-00195045 \\ https://hal.science/hal-00195045}

Submitted on 13 Dec 2007

HAL is a multi-disciplinary open access archive for the deposit and dissemination of scientific research documents, whether they are published or not. The documents may come from teaching and research institutions in France or abroad, or from public or private research centers.
L'archive ouverte pluridisciplinaire $\mathbf{H A L}$, est destinée au dépôt et à la diffusion de documents scientifiques de niveau recherche, publiés ou non, émanant des établissements d'enseignement et de recherche français ou étrangers, des laboratoires publics ou privés. 


\section{Transient climate change scenario simulation of the \\ Mediterranean Sea for the 21st century using a high- resolution ocean circulation model}

S. Somot, F. Sevault, M. Deque

S. SOMOT (corresponding author), F. SEVAULT, M. DÉQUÉ

Météo-France, Centre National de Recherches Météorologiques, 42 avenue G.

Coriolis, 31057 Toulouse cedex 1, France

Email: samuel.somot@meteo.fr

Tel: $00+33561079362$

Fax: $00+33561079610$

Climate Dynamics, submitted, July, 2004 


\section{Abstract}

A scenario of the Mediterranean Sea is performed for the $21^{\text {st }}$ century based on an ocean modelling approach. A climate change IPCC-A2 scenario run with an atmosphere regional climate model is used to force a Mediterranean Sea high resolution ocean model over the 1960-2099 period.

For comparison, a control simulation as long as the scenario has also been carried out under present climate fluxes. This control run shows air-sea fluxes in agreement with observations, stable temperature and salinity characteristics and a realistic thermohaline circulation simulating the different intermediate and deep water masses described in the literature.

During the scenario, warming and saltening are simulated for the surface $\left(+3.1^{\circ} \mathrm{C}\right.$ and $+0.48 \mathrm{psu}$ for the Mediterranean Sea at the end of the $21^{\text {st }}$ century) and for the deeper layers $\left(+1.5^{\circ} \mathrm{C}\right.$ and +0.23 psu on average $)$. These simulated trends are in agreement with observed trends for the Mediterranean Sea over the last decades. In addition, the Mediterranean thermohaline circulation (MTHC) is strongly weakened at the end of the $21^{\text {st }}$ century. This behaviour is mainly due to the decrease in surface density and so the decrease in winter deep water formation. At the end of the $21^{\text {st }}$ century, the MTHC weakening can be evaluated as $-40 \%$ for the intermediate waters and $-80 \%$ for the deep circulation with respect to present-climate conditions. The characteristics of the Mediterranean Outflow Waters flowing into the Atlantic Ocean are also strongly influenced during the scenario. 


\section{Introduction}

According to the Third Assessment Report of the Intergovernmental Panel on Climate Change (IPCC 2001), the climate over the Mediterranean basin may become warmer and drier during the $21^{\text {st }}$ century. These two effects could counteract each other with regards to the possible evolution of the Mediterranean Sea thermohaline circulation. Indeed, the impact of warmer and saltier surface waters on the density is unknown. The Mediterranean ThermoHaline Circulation (MTHC in the following) is driven by heat and water losses at the sea surface (Wüst 1961). This buoyancy flux leads to an anti-estuarine circulation with fresh and warm water getting into the Mediterranean Sea across the Gibraltar Strait at the surface and salty and cold water getting out in a deeper layer. With such a THC, at least one deep water formation area is needed as a key process for driving the vertical circulation. In fact, three main areas of intermediate or deep water mass formation have been reported in the Mediterranean Sea: the Gulf of Lions also called the MEDOC area (MEDOC Group 1970; Schott et al. 1996) where the Western Mediterranean Deep Water (WMDW) is formed, the Levantine basin (eastern part of the Mediterranean Sea) where the Levantine Intermediate Water (LIW, Lascaratos et al. 1993) and the Levantine Deep Water (LDW, Ozsoy et al. 1993) are formed, and the Adriatic Sea (Artegiani et al. 1997) which is the main source of the Eastern Mediterranean Deep Water (EMDW). In the Adriatic Sea, two deep water masses are formed during the winter season: the first one comes from the northern Adriatic and flows to the southern Adriatic, where open-sea deep convection takes place. Then, the newly formed Adriatic Deep Water (ADW) exits through the Strait of Otranto into the Ionian Basin and becomes the EMDW (Artegiani et al. 1997).

Past-climate and sensitivity studies have proved that the MTHC can show multiple equilibria and may even be unstable (Myers et al. 1998; Myers and Haines 2002). The 
formation of Sapropels is evidence that the MTHC was shutdown, or at the least very weak in the past (Béthoux 1993). More recently, the so-called Eastern Mediterranean Transient (EMT) has proved that the source of the EMDW can switch from the Adriatic Sea to the Aegean Sea during some years (Roether et al. 1996; Klein et al. 1999, Nittis et al. 2003, Rupolo et al. 2003). This recent change seems to have many impacts on water mass structures and properties (Klein et al. 1999; Lascaratos et al. 1999; Manca et al. 2003) as well as on the biogeochemistry (Klein et al. 2003).

A weakening or strengthening of the MTHC due to climate change is therefore possible and could have an impact on the Mediterranean sea surface temperature (SST) and consequently on the climate of the surrounding areas. Through the Mediterranean Outflow Waters (MOW), MTHC changes can moreover influence the Atlantic Ocean and hence the Atlantic THC (Curry et al. 2003; Potter and Lozier 2004). A strong impact on the Mediterranean marine ecosystems is likely.

The MTHC time scale (70 years, see Pickard and Emery, 1994) is smaller than for the global THC (1000 years). So, the impact of a MTHC modification can be visible more rapidly in the Mediterranean water mass characteristics than for the Atlantic. Many authors have reported a warming and salting of the Mediterranean deep waters over the last decades (e.g. Béthoux et al. 1990; Rohling and Bryden 1992; Fuda et al. 2002) and more recently of the MOW in the Atlantic Ocean close to the Gibraltar Strait (Potter and Lozier 2004) as well as far from it (Curry et al. 2003). Béthoux et al. (1998) attribute these trends to global warming. Until now, past-climate studies and sensitivity studies of the MTHC have been done (Myers et al. 1998; Thorpe and Bigg 2000; Myers and Haines 2002; Matthiesen and Haines 2003) but, to our knowledge, no realistic climate change scenario for the $21^{\text {st }}$ century with all forcings has been tested for the Mediterranean Sea. We try to address this issue in the present study. 
Modelling the MTHC requires high horizontal and vertical resolution. Small-scale advective and convective processes, small-scale atmospheric forcings and narrow straits have to be resolved to allow for a good representation of the various water masses formation and mixing processes as proved by many authors (e.g. Wu and Haines 1996; Wu and Haines 1998; Castellari et al. 2000; Brankart and Pinardi 2001). These time and space-scale constraints require the design of a downscaling strategy that allows us to assess the impact of a transient IPCC-A2 (IPCC 2001) climate change scenario on the MTHC during the $21^{\text {st }}$ century. The hierarchy of models needed for this strategy is presented in section 2. A present climate validation for the Mediterranean Sea model is shown in section 3. The climate change results focusing on the MTHC evolution are studied in section 4, the results are discussed in section 5 and we conclude in section 6.

\section{Models and simulations}

\subsection{Dynamical downscaling strategy}

A hierarchy of three different models is used to allow for a dynamical downscaling of an IPCC-A2 climate change scenario (IPCC 2001) for the Mediterranean Sea over the $21^{\text {st }}$ century.

An initial 140-year low resolution coupled simulation has been performed with an Atmosphere-Ocean General Circulation Model (AOGCM) under IPCC-A2 scenario forcings (greenhouse gases and aerosols concentration). Then, a high resolution Atmosphere Regional Climate Model (ARCM) has been used to obtain high resolution air-sea fluxes over the Mediterranean Sea. This simulation uses IPCC-A2 forcings and SST anomalies coming from the AOGCM run. Finally, a Mediterranean Sea simulation has been carried out with a high resolution Ocean Regional Circulation 
Model (ORCM) limited to the Mediterranean Sea. This simulation has been performed using forcings coming from the AOGCM and ARCM simulations. This downscaling strategy and the links between the three models are displayed in figure 1. The downscaling method used in this paper is a one-way nesting strategy. This means that the ORCM results do not influence the ARCM and AOGCM results during the scenario. In reality, the Mediterranean Sea could have an impact on the global climate through its SST and through the MOW flowing into the Atlantic Ocean, as discussed in section 5 .

\subsection{The global coupled model}

The AOGCM used in this study is developed at CNRM (Centre National de Recherches Météorologique, Toulouse, France), coupling the ARPEGE atmosphere model (Déqué et al. 1994) and the OPA ocean model (Madec et al. 1998). This model has been used to simulate the end of the $20^{\text {th }}$ century and different $21^{\text {st }}$ climate change scenarios following the Third Assessment Report of the Intergovernmental Panel on Climate Change (IPCC 2001). Royer et al. (2002) and Douville et al. (2002) described in detail the model and the study of the IPCC-B2 scenario. In the present study, we use the IPCC-A2 scenario and the associated twin simulation. In this twin simulation (also called control run), the greenhouse gases and aerosols concentrations are kept fixed at their 1950 level. The IPCC-A2 scenario is a pessimistic scenario in which the $\mathrm{CO}_{2}$ concentration is about $815 \mathrm{ppm}$ in 2099 instead of $602 \mathrm{ppm}$ in the IPCC-B2. The IPCC-A2 scenario has been chosen because it has become a standard for regional climate intercomparison projects (Christensen et al. 2002). As shown in figure 1, the AOGCM is used to provide SST anomalies, as well as anomalies of 3D temperature and salinity in the Atlantic Ocean, to the other models. 


\subsection{The atmosphere regional climate model}

Regional climate simulations can be performed with high-resolution AGCMs (Cubasch et al. 1995), nested regional climate models (Giorgi and Mearns 1999), or statistical downscaling (Wilby et al. 1998). In the present study, we use the first method, which offers advantages in providing globally consistent simulations. However, in this experiment, the high-resolution was restricted to the Mediterranean Basin in using the variable resolution version (or stretched version) of the ARPEGE model (Déqué and Piedelievre 1995). This stretching ability means that this version of ARPEGE is at the same time an AGCM because it is global and an ARCM because of its high resolution over the area of interest.

The model used here is the same as in Gibelin and Déqué (2003) and we just recall here its main features. It uses a semi-lagrangian advection scheme with a two timelevel discretization. The spectral truncation is T106, with 31 vertical levels located mainly in the troposphere (exactly those of the ERA15 reanalysis, Gibson et al. 1997). The time step is $30 \mathrm{~min}$. The pole of stretching is at the centre of the Mediterranean basin $\left(40^{\circ} \mathrm{N}, 12^{\circ} \mathrm{E}\right)$ and the stretching factor is 3 . The grid has 120 pseudo-latitudes and 240 pseudo-longitudes (with a reduction near the pseudo-poles to maintain the isotropy of the grid). As a result, the maximum horizontal resolution is $0.5^{\circ}$, that is to say about $50 \mathrm{~km}$ over the Mediterranean Basin, and reaches a minimum of $4.5^{\circ}$ in the Pacific.

Déqué and Piedelievre (1995) and Machenhauer et al. (1998) have shown that the stretched version of ARPEGE realistically reproduces seasonal and geographical variations of the main climatological parameters over Europe. The climate simulation is reasonably close to the CRU climatology (New et al. 1999) over Europe and around the Mediterranean Basin as shown by Gibelin and Déqué (2003). The largest 
deficiency is a too rainy winter. More details about the precipitation field can be found in Frei et al. (2003) and about the water cycle in Hagemann et al. (2004).

The model set-up (SST and radiative forcing) is the same as in Gibelin and Déqué (2003), except that the IPCC scenario is A2 instead of B2. A 140-year Atmosphere Scenario (1960-2099) called AS in the following has been run. Its main characteristics are summarized in table 1 .

The SST used by the ARCM are given by the coarser resolution AOGCM simulations, and the atmosphere is assumed to be in equilibrium with the oceans and sea ice. The consistency of large-scale circulation patterns between ARCM and AOGCM simulations has been verified in Gibelin and Déqué (2003). Indeed, the physical parameterizations, which calculate the surface fluxes are the same in the AOGCM and in the ARCM.

In the ARCM, the year numbering only corresponds to the SST chronology. Due to the chaotic behaviour of the atmosphere and to the low level of variability explained by the SST, a climate model year does not correspond to the actual year with same number.

\subsection{The high resolution Mediterranean Sea model}

A Mediterranean Sea limited area version of the primitive equation numerical model Ocean PArallel (OPA, Madec et al. 1998) has been developed. This model, called OPAMED8 (Somot 2005), is based on the 8.1 version of OPA and consequently is very close to the one developed for the MERCATOR project (Béranger et al. 2004; Drillet et al. 2005).

The horizontal eddy diffusivity and viscosity coefficients are fixed to $-1.210^{10} \mathrm{~m}^{4} / \mathrm{s}$ for tracers (temperature, salinity) and dynamics (velocity) with the use of a biharmonic operator. A 1.5 turbulent closure scheme is used for the vertical eddy diffusivity (Blanke and Delecluse 1993) and the vertical diffusion is enhanced to 1 
$\mathrm{m}^{2} / \mathrm{s}$ in case of unstable stratification. The role of these choices as a source of uncertainty in assessing the MTHC response to climate change is discussed in section 5.2. The density is a function of the potential temperature relative to the sea surface, the practical salinity and the pressure (Jackett and McDougall, 1995). The C grid in Arakawa's classification (Arakawa 1972) is used for the discretization. The bathymetry is based on the ETOPO5'x5' data base (Smith and Sandwell 1997). The rigid lid hypothesis is applied at the surface. A free-slip lateral boundary condition is used and the bottom friction is quadratic. A time step of 20 minutes is applied.

The horizontal resolution of OPAMED 8 is $1 / 8^{\circ} \times 1 / 8^{\circ} \cos (\phi)$ with $\phi$ latitude. This is equivalent to a range of 9 to $12 \mathrm{~km}$ from the north to the south of the model with square meshes. It has 43 vertical Z-levels with an inhomogeneous distribution (from $\Delta \mathrm{Z}=6 \mathrm{~m}$ at the surface to $\Delta \mathrm{Z}=200 \mathrm{~m}$ at the bottom with 25 levels in the first 1000 $\mathrm{m})$. The maximum depth is $4100 \mathrm{~m}$ in the Mediterranean Sea (Eastern Basin).

The OPAMED8 grid is tilted and stretched at the Gibraltar Strait to better follow the SW-NE axis of the real strait. The Gibraltar Strait is represented with a two grid-point wide strait.

\subsection{Mediterranean Sea scenario simulation}

In this study, a 140-year simulation (1960-2099), called Mediterranean Scenario (MS) is performed. For this run, three kind of boundary forcings are applied to OPAMED8: the air-sea fluxes, the river runoff fluxes including the Black Sea and the Atlantic Ocean characteristics.

\subsubsection{Surface forcing}

The whole period of ARCM run (1960-2099) provides the air-sea fluxes for the Mediterranean Scenario as seen in figure 1. We have extracted daily momentum, 
water and heat fluxes from the AS simulation at a $0.5^{\circ}$ resolution over the Mediterranean Sea. The OASIS2.4 tool (Valcke et al. 2000) is used to interpolate the fields from the atmosphere to the ocean model grid.

Air-sea fluxes change every day and are constant over a 24-hour period. Consequently, the diurnal cycle is not resolved by OPAMED8. Water fluxes coming from the atmosphere model are transformed into virtual salt fluxes by dilution in the upper model level with respect to the rigid lid hypothesis.

The heat flux is adjusted to the ORCM SST by a surface relaxation towards the daily SST used by the ARCM (section 2.3). This term is actually a first order coupling between the SST of the ocean model and the atmosphere heat flux. This term ensures a consistency between surface heat fluxes coming from the ARCM and SST calculated by the ORCM. The relaxation coefficient is $-40 \mathrm{~W} / \mathrm{m}^{2} / \mathrm{K}$, as defined in Barnier et al. (1995). It is equivalent to an 8-day restoring time scale, similar to those used in previous studies (e.g. Korres et al., 2000, 5-day restoring term). With this value, the relaxation is not too strong and the ocean model is able to create and maintain small scale structures and to create interannual SST variability.

\subsubsection{River runoff fluxes}

No salinity damping is used at the surface of OPAMED8 and a salt flux due to river runoff is explicitly added to complete the salt budget. For the present-climate period (1960-1999), a monthly mean climatology is computed from the RivDis database (Vörösmarty et al. 1996) for the main 33 rivers of the Mediterranean Sea catchment basin.

The Black Sea is not included in OPAMED8. Nevertheless, this sea can be considered as one of the major freshwater sources for the Mediterranean Sea. It is in fact a salt sink in this model configuration. As with the Gibraltar Strait, the exchange between 
the Black Sea and the Aegean Sea consists of a two layer flow across the Sea of Marmara and the Dardanelles Strait. In this study, we assume that this two layer flow can be approximated by a freshwater flux diluting the salinity of the mouth grid point. Thus the Black Sea is considered as a river for the Aegean Sea. The monthly mean equivalent water flux towards the Aegean Sea is computed as the water budget over the Black Sea surface : Precipitation + Black Sea River Runoff - Evaporation. This parameterization is based on the data collected by Stanev et al. (2000) and assumes that the sea level of the Black Sea does not change.

In the scenario, the RivDis runoff has been modified according to AS hydrological fluxes (see figure 1), in a way that is consistent with what is done for SST. We compute yearly mean multiplying factors to modify the runoff of each river. Each factor is a ratio between the value of a given year and the present climate value. Then the factor time series (2000-2099) is filtered as in Gibelin and Déqué (2003) to obtain 10 decadal values for the $21^{\text {st }}$ century. Table 2 shows these values for the main rivers and for the Black Sea. Details can be found in Somot and Sevault (2005). The main decrease is for the Black Sea, and we can expect an impact on the Aegean Sea salinity. Note that for the Nile, the value remains almost unchanged.

\subsubsection{The Atlantic Ocean}

Another forcing of OPAMED8 is a buffer zone which simulates the Atlantic Ocean west of the Gibraltar Strait. Before 2000, temperature and salinity in this area are relaxed towards the seasonal 3D Reynaud climatology (Reynaud et al., 1998) by means of a Newtonian damping term in the tracer equation equal to $-\left(\mathrm{X}_{\text {model }}-\mathrm{X}_{\text {climatology }}\right) / \tau$. The restoring term is weak close to Gibraltar $(\tau=100$-day time scale at $\left.7.5^{\circ} \mathrm{W}\right)$ and stronger moving away from it $\left(\tau=3\right.$ days at $\left.11^{\circ} \mathrm{W}\right)$. 
For the scenario (2000-2099), the temperature and salinity climatology is modified similarly to the SST and the river runoff (Somot and Sevault 2005). The computation is based on the ocean data from the AOGCM scenario (see figure 1).

\subsubsection{Initial conditions and spin-up}

The initial conditions are provided by the MEDATLAS-II monthly climatology for the Mediterranean Sea (MEDAR/MEDATLAS Group, 2002) and by a seasonal climatology (Reynaud et al., 1998) for the Atlantic part of the model. We start our simulation in August when the vertical stratification is the most stable to avoid a possible strong and non-physical initial mixing.

A 20-year spin-up has been performed under present climate conditions before launching the MS simulation in order to obtain a quasi-equilibrium. For this spin-up, OPAMED8 is forced two times successively by the interannual fluxes of the 19601970 period.

\subsection{Mediterranean Sea control simulation}

A 140-year additional experiment, called Mediterranean Control run (MC in the following) has been carried out to verify the model stability.

The interannual air-sea fluxes of the 1960-1980 period of the AS simulation are used to force this control simulation. This 20 -year long forcing is repeated 7 times to obtain a simulation as long as MS. The MC years are counted from 1960 to 2099. The other forcings (river runoff, Black Sea runoff and buffer zone) are the same as for the MS simulation before 2000. Initial conditions and spin-up are also identical. Consequently, these two simulations begin to diverge only from the year 1980. MC and MS characteristics are summarized in table 1.

The MC run allows for the evaluation of the stability of the ORCM over a long period of time under present-climate conditions. Moreover, the difference between MS and 
MC gives an unbiased evaluation of the climate change impact in case of a drift in MC.

For the majority of the analysed variables, we will show two curves on the same figure, one of the temporal evolution of the variable in the control run and the other of the temporal evolution in the scenario. The scenario is a transient simulation that does not reach equilibrium even at the end of the $21^{\text {st }}$ century. The use of a classical time average is not advisable to analyse such curves or to compare it to the control run curves. Instead we have performed an exponential fit (least square method) of all the variables showing a temporal trend in the scenario. The choice of an exponential fit comes from the exponential growth of the GHG concentration during the A2 scenario (rate of change equal to about $1.4 \%$ per year). The fitted curves are represented by dashed line in each time series (see figure 2 and 3 for example). In the text and in the tables, we always use the value of the last year of the fitted curves that is to say 2099. From this approach, we can extract rates of change (in percentage per year) for the various analysed physical quantities and then we can discuss their stability during the scenario (see section 4). For the validation of the control run (section 3), we use a linear fit in order to prove the stability of the simulation. As indicated in the tables, the slope of the MC fit is often non significantly different from zero. Then the 2099 value practically always corresponds to the 2070-2099 time average. The 2099 fitted value also allows us to filter the interannual variability of the system. In the same figures, a confidence interval at a 95\% level has also been plotted around the fitted values of the control run (Gaussian test). The number of independent values is equal to 20 due to the design of the control run. To compute the confidence interval, the standard deviation with respect to the fitted curve has been used. This allows us to 
know if the difference between the control run and the scenario is statistically significant and when this significance level is reached.

\section{Present climate validation}

The main goal of this part is to quantify the stability of OPAMED8 over a long run under present-climate conditions. We also validate here OPAMED8 against observations for fields useful for representing the MTHC, namely air-sea fluxes, surface and integrated temperature and salinity characteristics, mixed layer depth, water mass formation rate and water volumes transported by the MTHC.

\subsection{Air-sea fluxes}

Validating the air-sea fluxes is a difficult task because of the lack of spatial and temporal high resolution observed data. Nevertheless, for the Mediterranean Sea, some direct measurements exist and strait transport measurements give us indirect information about surface fluxes. For example, the long term heat and water balance between the Gibraltar Strait transport and the Mediterranean Sea surface flux (Béthoux 1979; Bunker 1982) allows us to obtain indirect observations of the basin integrated value of the surface fluxes. Consequently, for validation, we focus on the spatial average of the MC run over the whole Mediterranean basin. Table 3 summarizes the air-sea flux values computed by means of a linear fit as explained in section 2.6. As the control run is very stable, the 2099 fitted values are practically equal to a classical 30-year average over 2070-2099, for example.

For the MC run (2099 fitted value), the Mediterranean surface heat loss is equal to $-6.2 \mathrm{~W} / \mathrm{m}^{2}$ including the SST relaxation term which amounts to $31.5 \mathrm{~W} / \mathrm{m}^{2}$. The value $-6.2 \mathrm{~W} / \mathrm{m}^{2}$ with an interannual standard deviation of $5.8 \mathrm{~W} / \mathrm{m}^{2}$ is in good agreement with those found in the literature. From direct measurement, Béthoux (1979) gives a 
value of $-7 \pm 3 \mathrm{~W} / \mathrm{m}^{2}$ for the surface heat flux. This value of $-7 \mathrm{~W} / \mathrm{m}^{2}$ is confirmed by Bunker et al. (1982). The same authors found a value of $+5 \mathrm{~W} / \mathrm{m}^{2}$ for the Gibraltar heat transport whereas later measurements suggest a range of $5.3-6.2 \mathrm{~W} / \mathrm{m}^{2}$ (MacDonald et al. 1994).

In an ocean model study including the SST relaxation term, Wu and Haines (1998) give a value of $-5.8 \mathrm{~W} / \mathrm{m}^{2}$ for the two terms (40-year average after reaching a steady state). In the same kind of study, Castellari et al. (2000) obtain $-9.8 \mathrm{~W} / \mathrm{m}^{2}$ for the surface flux (experiment D) and Brankart and Pinardi (2001) a value of $-4 \mathrm{~W} / \mathrm{m}^{2}$. In the latter study, they forced their model with the 1945-1993 observed COADS heat flux (da Silva et al. 1995) with a damping term equal to $-25 \mathrm{~W} / \mathrm{m}^{2} / \mathrm{K}$. Disregarding SST relaxation, the COADS 49 -year averaged heat flux is equal to $+10 \mathrm{~W} / \mathrm{m}^{-2}$. Two other atmospheric datasets have been recently used by Josey (2003): the Southampton Oceanography Centre (SOC) flux climatology (Josey et al. 1999) with an integrated heat flux of $+6 \mathrm{~W} / \mathrm{m}^{-2}$ and the National Center for Environmental Prediction/National Center for Atmospheric Research (NCEP/NCAR) atmospheric model 1949-2002 reanalysis (Kistler et al. 2001) which gives a value of $+2 \mathrm{~W} / \mathrm{m}^{-2}$. Consequently, the atmospheric datasets based on observed values, atmospheric reanalyses or climate models seem to be unable to produce accurate air-sea fluxes for the Mediterranean Sea. The SST relaxation term is thus necessary to force an ocean model. With this term, the OPAMED8 heat flux averaged over the Mediterranean Sea is in good agreement with the in-situ measurements.

The other important buoyancy forcing is the water flux (Evaporation - Precipitation River input) at the surface. For this flux, the spread of the observed values found in the literature is larger than for the heat flux: the larger water loss is given by Béthoux (1979) with a deficit of $0.95 \mathrm{~m} / \mathrm{year}$ and the smaller by Garrett (1996) with 0.52 
m/year. In the present study, the E-P-R water loss amounts to $0.72 \mathrm{~m} /$ year (about 2.0 $\mathrm{mm} /$ day with an interannual standard deviation of $0.2 \mathrm{~mm} /$ day), which is in the observed range and very close to the value given in Gilman and Garrett (1994): $0.71 \pm$ $0.07 \mathrm{~m} /$ year. Our value is also in agreement with the value $-0.67 \mathrm{~m} /$ year obtained by Wu and Haines (1998) in a modelling study with a surface salinity relaxation towards observed data. However, thanks to the GIBEX experiment at Gibraltar, Bryden and Kinder (1991) obtain a value of the Gibraltar Strait water transport which is equivalent to a E-P-R loss between 0.56 and $0.66 \mathrm{~m} /$ year.

With the UNESCO database used in our study, the river runoff fluxes plus the Black Sea contribution is equal to $0.18 \mathrm{~m} /$ year and the E-P term is equal to $0.90 \mathrm{~m} / \mathrm{year}$. This value seems to be overestimated with respect to the latest values given by Josey (2003) for atmospheric datasets. He obtained E-P $=0.74 \mathrm{~m} / \mathrm{year}$ for the SOC climatology and $0.70 \mathrm{~m} /$ year with the NCEP/NCAR reanalysis.

The stability of the surface fluxes as well as their interannual variability can be seen in figure 2 for the heat flux in $\mathrm{W} / \mathrm{m}^{2}$ and figure 3 for the water flux in $\mathrm{mm} / \mathrm{day}$ for the 1960-2099 period of MC (grey curve). Table 3 summarizes the heat and water surface fluxes for the Mediterranean Sea and for various sub-basins where deep water formation may occur (Gulf of Lions, Levantine Basin, Adriatic Sea, Aegean Sea). These sub-basins are defined in figure 4a. Computing the buoyancy flux (see Marshall and Schott, 1999, equation (6), for the formula) allows us to understand the respective role of the water and heat terms in forcing the THC in each sub-basin. For the whole Mediterranean Sea, the buoyancy flux is negative in our notation. This means that water masses become denser due to air-sea fluxes over the Mediterranean Sea, that is to say that they lose buoyancy. Note that some authors express the buoyancy flux as a 
density flux by multiplying it by $-\mathrm{g} / \rho$ with $\mathrm{g}$ the acceleration due to gravity and $\rho$ the density (Josey 2003).

The salt forcing seems to be more important than the heat forcing, resulting in $70 \%$ of the total buoyancy flux. This average behaviour masks the seasonal and the interannual variability where the heat term dominates as noted by Josey (2003). For example, in winter, the heat term represents more than $80 \%$ of the total with a value of $-39.610^{-9} \mathrm{~m}^{2} \cdot \mathrm{s}^{-3}$. Additionally, each sub-basin has its own different characteristics. For example, the deep water formation occurring in the Gulf of Lions seems to be mainly due to the heat forcing. Indeed, the yearly mean buoyancy flux due to the heat term is equal to $-11.010^{-9} \mathrm{~m}^{2} \mathrm{~s}^{-3}$, which amounts to $2 / 3$ of the total buoyancy flux. The situation is completely different in the Levantine Basin with about $90 \%$ of the total buoyancy flux due to the salt flux. The Adriatic Sea and the Aegean Sea show a surface water gain due to the Po and Black Sea runoffs. In these sub-basins, the heat loss (negative buoyancy flux) dominates the water gain (positive buoyancy flux) and it is responsible for the density increase and the sinking of the surface waters. Comparing the evolution of the water and heat term of the buoyancy flux under climate change conditions is one of the key-points in assessing the question of the future evolution of the MTHC as shown in section 4.1.

\subsection{Sea surface characteristics}

The temperature and salinity sea surface characteristics for the whole Mediterranean Sea and for various sub-basins are presented in table 4 (for the model runs, 2099 fitted values are used). Climatological values coming from the MEDATLAS-II database (MEDAR/MEDATLAS Group, 2002) have also been added in this table for validation, as well as the observed SST used for the ORCM surface relaxation (the socalled RSST, Smith et al. 1996). For the whole basin, the model shows a cooling bias of $-1.0^{\circ} \mathrm{C}$ with respect to the MEDATLAS-II data and $-0.8^{\circ} \mathrm{C}$ with respect to the 
RSST. The drift leading to this bias occurred during the OPAMED8 spin-up and then MC is very stable in SST from 1960 to 2099 (figure not shown). This initial drift is due to the too strong Mediterranean net heat loss $\left(-37.7 \mathrm{~W} / \mathrm{m}^{2}\right.$ in average $)$ simulated by ARPEGE without the SST relaxation. In the deep water convective areas, the bias is always less than $1^{\circ} \mathrm{C}$ with respect to the RSST.

The sea surface salinity (SSS) is in very good agreement with the MEDATLAS-II database with a bias equal to +0.02 psu for the whole basin. This result validates the ARPEGE E-P-R flux of $0.72 \mathrm{~m} / \mathrm{year}$. The SSS bias is very weak in all sub-basins except for the Adriatic Sea where the bias is 0.68 psu. Because of the SSS bias, results concerning the Adriatic Sea have to be considered with care. Nevertheless, the general good agreement with the climatology has to be underlined, especially for the salinity, because this Mediterranean Sea model is forced by explicit river runoff fluxes without any relaxation towards SSS observed values.

The surface salinity map of the MEDATLAS-II database in winter is shown in figure 4a and can be compared with the OPAMED8 surface salinity in figure $4 \mathrm{~b}$ (averaged over the last 30 years of MC). The areas of maximum SSS, namely the north of the Algero-Provençal basin, the southern Adriatic Sea and the northern Levantine basin are the signature of the open-sea deep water formation areas. Comparing these two maps, the good agreement of the spatial patterns can be seen, apart from the Adriatic Sea where the Po river freshwater input does not seem to be large enough to decrease the SSS as in the climatology.

\subsection{Averaged temperature and salinity}

To study the MTHC, not only the T-S surface characteristics have to be validated but also the $3 \mathrm{D}$ averaged temperature (called $<\mathrm{T}>$ in $\left.{ }^{\circ} \mathrm{C}\right)$ and salinity $(<\mathrm{S}>$ in psu). For a given sub-basin with a volume $\mathrm{V},\langle\mathrm{T}\rangle$ is computed through the following equation: 
$<T>=\frac{\iiint_{V} T(x, y, z) d x d y d z}{\iiint_{V} d x d y d z}$.

The values of $\langle\mathrm{T}\rangle$ and $\langle\mathrm{S}\rangle$ have been computed for the different sub-basins defined in figure $4 \mathrm{a}$ and are summarized in table 4 using the same fitting method as before.

Comparing with the MEDATLAS-II database, we show that our model is generally too cold $\left(0.5^{\circ} \mathrm{C}\right.$ in average over the whole basin) due to the surface behaviour and that the $3 \mathrm{D}$ salinity is well reproduced. For the averaged temperature, the most biased basins are the Aegean basin $\left(-0.9^{\circ} \mathrm{C}\right)$ and the Adriatic sea $\left(-0.8^{\circ} \mathrm{C}\right)$, the two shallowest basins. For the salinity, the maximum bias occurs in the Gulf of Lions with a fresh bias of -0.10 psu. This bias is probably due to a too weak LIW inflow at an intermediate depth in this area. This failing was already mentioned in other modelling studies (Wu and Haines 1996; Castellari et al. 2000).

As for the surface characteristics, the major part of these biases appear during the 20year OPAMED8 spin-up and figures 5 and 6 prove that the 3D averaged temperature and salinity of the model are remarkably stable over the 140-year control simulation for the whole Mediterranean Sea. The same behaviour is observed for all individual sub-basins (figures not shown). For the whole Mediterranean Sea, the drift of $\langle\mathrm{T}\rangle$ is equivalent to $-0.11^{\circ} \mathrm{C} /$ century and the drift for $\langle\mathrm{S}>$ to $+0.02 \mathrm{psu} /$ century. We will see that this is less than the climate change signal by more than one order of magnitude.

\subsection{THC characteristics}

\subsubsection{Methods}

Validating the THC is difficult because of the lack of high resolution and long-term observed data at depth. However, the Mediterranean Sea has been observed for a long time and many authors have reported the geography of the different winter convective 
areas and the maximal depth that the convection can reach. Some have also tried to compute the formation rates of the different Mediterranean water masses. The maximum value of local overturning stream functions is used to evaluate the deep circulation. In this section, these four different approaches of the MTHC are used to validate OPAMED8.

Figure 7a shows the winter (JFM) mixed layer depth (MLD) averaged over the 20702099 period of the MC run. The MLD computation is based on a turbulent kinetic energy criterion instead of a $\Delta \rho$ criterion. The robustness of the criterion is discussed in section 5.3.

The shaded areas identify the areas of winter open-sea convection which are those mentioned in the literature, namely, the Gulf of Lions (MEDOC Group 1970; Schott et al. 1996), the southern Adriatic Sea (Artegiani et al. 1997), the Levantine basin (Lascaratos et al. 1993) and the Aegean Sea (Roether et al. 1996). The winter convection is a process known to be very variable from one year to another (Marshall and Schott 1999) so the MLD averaged value can mask a different reality. The yearly evolution of the maximum depth reached by the monthly mean MLD for each convective area is shown in figures $8 \mathrm{a}, 8 \mathrm{~b}, 8 \mathrm{c}$ and $8 \mathrm{~d}$ (grey line) and the 2099 fitted values are in table 5. Note that deep water masses formed by shelf convection also exist in the Mediterranean Sea (see Artegiani et al. 1997 for the Adriatic Sea) but this diagnostic is not relevant for these water masses.

A water mass transformation diagnostic has also been computed using density classes. This diagnostic originates from the work by Walin (1982) carried out with temperature classes. This method was then adapted by Tziperman (1986) to density classes and was applied to the North Atlantic Ocean (Speer and Tziperman 1992) and to the Mediterranean Sea (Lascaratos 1993; Tziperman and Speer 1994, Rupolo et al. 2003, Somot 2005). The cross isopycnal buoyancy flux $(F(\rho)$ in $S v$, equation (1) in 
Rupolo et al. 2003) produced by surface heat and water fluxes has been computed for each convective area every month and then yearly averaged. Figure 9 shows the curve for the whole Mediterranean Basin and for a 2070-2099 average. Note that a density range of $0.10 \mathrm{~kg} \cdot \mathrm{m}^{-3}$ has been used. In this study, we will focus our analysis on the denser part of the curve representing the deep water formation process. The peak of minimum value shows that $3.8 \mathrm{~Sv}$ of dense water $(\rho>29.05)$ is formed in OPAMED8 by the surface fluxes. This value is in agreement with Lascaratos (1993) who gives a value of $4 \mathrm{~Sv}$ for the transformation peak even if it is with a 28.70 density. The surface heat flux (dotted line in figure 9) contributes more than the water flux (dashed line) to this dense water formation. It represents about $80 \%$ of the maximum formation peak.

For each year, the minimum value of $F(\rho)$ and the density of this minimum have been extracted. These values are the maximum rate of water mass formation and the minimum density of the newly formed waters. The temporal evolution of these two parameters has been computed over the 1960-2099 period (cf. figures 10a and 10b). The 2099 fitted values are summarized in table 6. These figures shows the stability of the control run in terms of water mass formation and the interannual variability of the formed water mass characteristics. The density of the peak ranges from 27.95 to 29.25 $\mathrm{kg} \cdot \mathrm{m}^{-3}$. The maximum rate is between 2.5 and $7 \mathrm{~Sv}$ with a $4 \mathrm{~Sv}$ mean.

The same calculation as in figure 9 has been done for all the convective areas (the Levantine Basin, the Adriatic Sea, the Gulf of Lions and the Aegean Sea defined in figure 4a). Sub-basin calculation has been justified by Lascaratos (1993). The curves averaged over the 2070-2099 period are not shown but the 2099 fitted values are in table 6. Results for the sub-basins are described below.

Next, we want to quantify the strength of the Mediterranean Sea thermohaline circulation (MTHC). The maximum of the meridional overturning stream function 
(MOF) is commonly used to assess the strength of the Atlantic THC in Sverdrup (1 $\left.\mathrm{Sv}=10^{6} \mathrm{~m}^{3} / \mathrm{s}\right)$. The MOF is a zonal integration from the western coast $\left(\mathrm{x}_{\mathrm{W}}\right)$ to the eastern coast $\left(\mathrm{x}_{\mathrm{E}}\right)$ of the meridional velocity $(\mathrm{v}(\mathrm{x}, \mathrm{y}, \mathrm{z}, \mathrm{t}))$ which is then vertically integrated from the bottom of the sea $\mathrm{H}(\mathrm{x}, \mathrm{y})$. This stream function in the verticalmeridional plane has the depth as a vertical coordinate and is given by the following equation:

$$
M O F=\frac{\int_{t_{0}}^{t_{1}} \int_{x_{W}}^{x_{E}} \int_{H(x, y)}^{z} v(x, y, z, t) \cdot d z \cdot d x \cdot d t}{t_{1}-t_{0}}
$$

where $t_{0}$ and $t_{1}$ are the start and end time of the time period, 1 year for example. It is possible to compute the $\mathrm{ZOF}$ (zonal overturning stream function) by replacing the meridional velocity with the zonal velocity $\mathrm{u}(\mathrm{x}, \mathrm{y}, \mathrm{z}, \mathrm{t})$ and by integrating from $\mathrm{y}_{\mathrm{S}}$ to $\mathrm{y}_{\mathrm{N}}$. A zonal overturning stream function (ZOF) has been used for the study of the MTHC by Myers and Haines (2002). Indeed, the MTHC is zonal in average because of the location of the Gibraltar Strait. The exchanges between the Levantine Basin, the Ionian Sea and the Western Basin can be studied with this Mediterranean ZOF. However, the MTHC is locally meridional. For example, a local MOF should be defined to study the WMDW formation and its circulation from the north to the south of the western basin. Another local MOF is required to take into account the ADW formation and its transformation into the EMDW. An example of the use of combined ZOF and MOF is given by Döös et al. (2004) for the Baltic Sea.

In figure 11a, we show the global Mediterranean ZOF averaged over the last 30 years of MC. This figure is similar to the figure 2 in Myers and Haines (2002). Figure 11c represents a local MOF called Adriatic MOF. It includes the Adriatic Sea and the northern part of the Ionian Sea limited to $37^{\circ} \mathrm{N}$. It will be used to study the ADW and the EMDW. Figure 11e shows the Western MOF including the northern part of the 
Western Mediterranean Sea limited to $38^{\circ} \mathrm{N}$ (Liguro-Provencal Basin and Tyrrhenian Sea). The deep circulation of the Tyrrhenian Sea is not well developed in our model and consequently the Western MOF allows the study of the WMDW. To better quantify our results, time series of maximum and minimum values of the different overturning stream functions have been computed for fixed sections defined in figure 4a: one section in the Mediterranean ZOF (section $\mathrm{F}$ at $21.7^{\circ} \mathrm{E}$, figure $12 \mathrm{a}$ ), two sections in the Adriatic MOF (section D at $40^{\circ} \mathrm{N}$, figure $12 \mathrm{~b}$ and section $\mathrm{E}$ at $37.1^{\circ} \mathrm{N}$, figure $12 \mathrm{c}$ ) and one section in the Western $\mathrm{MOF}$ (section $\mathrm{A}+\mathrm{C}$ at $40^{\circ} \mathrm{N}$, figure $12 \mathrm{~d}$ ). These maximum or minimum values give an index of the strength of the local MTHC. The validation of the different branches of the MTHC and the study of their evolution during the scenario is then possible with this diagnostic. For each time series, the 2099 fitted values are summarized in table 7.

A diagnostic based on overturning stream functions has been chosen because it allows us to quantify in Sverdrups and in depth the circulation changes between the control and the scenario. Moreover, the choice of any diagnostic based on density would be less appropriate for this climate change study because the vertical structure of the density field changed continuously during the scenario. Note that with this diagnostic, water masses formed by shelf convection are also taken into account.

\subsubsection{Levantine Intermediate Water}

The Rhodes Gyre, the area of the Levantine Intermediate Water formation, is clearly seen in figure $7 \mathrm{a}$. The maximum winter MLD in figure $8 \mathrm{a}$ shows strong interannual variability and a 2099 fitted value of 680m. As mentioned by Ozsoy et al. (1993), the Levantine Deep Water is sometimes formed in the same area as the LIW. However, most of the time, the water mass sinking stops at an intermediate depth as expected. Even if the slope of the MC curve in figure $8 \mathrm{a}$ is not statistically significantly different from zero, this figure shows one of the largest drift in $\mathrm{MC}$ with a shallowing 
of the maximum MLD during the run from $1200 \mathrm{~m}$ to about $700 \mathrm{~m}$. Actually, more LDW formation events occur at the beginning of the run than at the end. A 20-year spin-up does not seem to be long enough to stabilize the MLD in the Levantine Basin. The maximum LIW formation rate in 2099 (cf. table 6, Levantine Basin) is equal to 1.34 Sv (2099 fitted value) for water denser than 29.05. This value is in good agreement with previous studies. Indeed, with the same method, Lascaratos (1993) gives a value of $1.5 \mathrm{~Sv}$ for the maximum LIW formation rate. Tziperman and Speer (1994) confirm this value from a surface climatology data study; Lascaratos et al. (1993) give a value of 1.0 Sv with a mixed layer model and Castellari et al. (2000) a value of $1.5 \mathrm{~Sv}$ in a modelling study after the modification of the surface heat flux formulae (DS1 experiment). With a 100-year simulation, Myers and Haines (2000) obtained a LIW formation rate of $1.2 \mathrm{~Sv}$.

However, it is worth noting that the formation rate is highly dependent on the chosen threshold in density. For example, with a 28.92 value instead of 28.70, Lascaratos (1993) obtain a lower value for the LIW formation rate: $0.69 \mathrm{~Sv}$ instead of $1.5 \mathrm{~Sv}$. In the framework of a climate change scenario in which the deep water density is continuously changing, we have chosen to discuss the maximum formation rate. We therefore use the minimum value of the function (i.e. the maximum formation rate) and we do not fix any subjective density threshold. It is also impossible to separate the LDW formation from the LIW formation with this diagnostic.

Figure 11a shows two well developed THC cells in the Eastern Basin. The upper part of the positive cell corresponds to the Modified Atlantic Water (MAW) eastward circulation. The bottom part of the negative cell corresponds to the eastward transport of the EMDW. The LIW is located between the maximum value at $200 \mathrm{~m}$ and the minimum value at $1200 \mathrm{~m}$, representing the intermediate branch of the Eastern MTHC. This description corresponds to the observations since the pioneering work by Wüst 
(1961) and before the Eastern Mediterranean Transient (Roether et al. 1996). An estimate of the westward LIW transport can be obtained as the difference between the two extreme values. At $27.1^{\circ} \mathrm{E}$ (section F), the LIW transport is equal to $1.61 \mathrm{~Sv}$ (table7, 2099 fitted value). This transport is computed as the difference between the sub-surface maximum and the deep minimum of the $\mathrm{ZOF}$ at $21.7^{\circ} \mathrm{E}$ (see figure $12 \mathrm{a}$ ). This is in relatively good agreement with the formation rate but higher than the total westward transport of $0.8 \mathrm{~Sv}$ given by Myers and Haines (2000) across a vertical section at $25.5^{\circ} \mathrm{E}$.

\subsubsection{Adriatic Deep Water}

In OPAMED8, the south of the Adriatic Sea is a well mixed area in winter, as seen in figure 7a and the part of the Adriatic Deep Water due to open-sea deep convection is formed here. Figure $8 \mathrm{~b}$ shows strong interannual variability for the MLD maximum with a mean at about $800 \mathrm{~m}$ and some years for which the convection reaches the bottom. This behaviour corresponds to the observations (Artegiani et al. 1997).

The maximum ADW formation rate in 2099 is equal to $0.54 \mathrm{~Sv}$ for waters denser than 29.23 (cf. table 6). The maximum value of the MOF profile at $40^{\circ} \mathrm{N}$ (Otranto Strait, section D) is equal to $0.46 \mathrm{~Sv}$ (at $400 \mathrm{~m}$, fitted value) in agreement with the formation rate. The formation rate and overturning values are also in agreement with Lascaratos (1993, 0.34 Sv), Roether et al. (1994, $0.3 \pm 0.1 \mathrm{~Sv}), \mathrm{Wu}$ and Haines (1998, 0.44 Sv) and Castellari et al. (2000, 0.3 Sv). Figure 12b shows the interannual variability of the Adriatic MOF at $40^{\circ} \mathrm{N}$. For the control run, yearly mean values between $0.2 \mathrm{~Sv}$ and 1 Sv occur. The Adriatic THC is stable throughout the control run. Note that the MC curve is almost cyclic because of the OPAMED8 forcing is repeated with a 20-year period.

\subsubsection{Eastern Mediterranean Deep Water}


Eastern Mediterranean Deep Water is formed when ADW overflows the sill at the Otranto Strait (Klein et al., 1999; Stratford and Haines, 2000).

The Adriatic MOF (figure 11c) clearly shows the cascading of the ADW past the Otranto Strait between $39^{\circ} \mathrm{N}$ and $40^{\circ} \mathrm{N}$. The maximum overturning is located at $400 \mathrm{~m}$ in the Adriatic Sea whereas it is located at about $800 \mathrm{~m}$ in the Ionian Sea. Moreover non-negligible overturning values are seen down to a depth of $2500 \mathrm{~m}$. The time series at $37.1^{\circ} \mathrm{N}$ (section E, figure 12c) allows us to compute a southward transport of the EMDW. It is equal to $0.68 \mathrm{~Sv}$, higher than the $\mathrm{ADW}$ at Otranto because entrainment and mixing with LIW occurs during the overflow.

In figure 12a, the minimum value corresponds to the deep branch of the MTHC in the Eastern Mediterranean Sea. At $21.7^{\circ} \mathrm{E}$ (section F), an eastward EMDW transport of $0.60 \mathrm{~Sv}$ is simulated by OPAMED8. This proves the ability of OPAMED8 to ventilate the EMDW from its formation area to the rest of the basin. Myers ad Haines (2000) obtain a value of $0.1 \mathrm{~Sv}$ of eastward transport across a vertical section at $25.5^{\circ} \mathrm{E}$, associating it with the EMDW transport. Note that significant EMDW transport exists down to about $3000 \mathrm{~m}$ in OPAMED8.

Even if the Aegean Sea is identified as a convective area in winter in our model simulation (see figure 7a and figure 8d), no EMT-like circulation is found in MC (Roether et al. 1996; Klein et al. 1999). Waters formed in the Aegean Sea in winter (maximum formation rate of $1.04 \mathrm{~Sv}$ ) are not dense enough to overflow into the Levantine Basin and reach the bottom. In MC, the water masses formed in the Adriatic Sea are denser than in the Aegean Sea and less mixed at the strait sill.

\subsubsection{Western Mediterranean Deep Water}

In figure 7a, the Gulf of Lions is shown as the major site of open-ocean deep water mass formation for the Mediterranean Sea as mentioned by Marshall and Schott (1999). For this area, figure 8c shows that the convection reaches a depth greater than 
$2000 \mathrm{~m}$ most of the time. Only some rare years do not show convection deeper than $500 \mathrm{~m}$. The two situations have been reported in the observations (Mertens and Schott 1998; Marshall and Schott 1999) and have been simulated (Castellari et al. 2000). Mertens and Schott (1998) show that the convection reached the bottom about 2 years out of 3 whereas Castellari et al. (2000) obtain a bottom convection only 1 year out of 3. Our simulation is closer to the observed results of Mertens and Schott (1998).

The maximum WMDW formation rate is equal to $0.93 \mathrm{~Sv}$ for waters denser than 28.91. When we compare with other studies, the WMDW formation rate seems to be overestimated with respect to the value of $0.3 \mathrm{~Sv}$ of Lascaratos (1993). However it is in agreement with Tziperman and Speer (1994, 1 Sv). From a modelling study for which the sea surface salinity climatology used for relaxation has been modified, Castellari et al (2000) obtain three different values with various parameterizations of the surface heat fluxes: 1.6 Sv (DS experiment), 1.1 Sv (DS2 experiment) and 0.2 Sv (DS1 experiment).

The overturning stream function shows a maximum value of $0.5 \mathrm{~Sv}$ on average over the last 30 years of MC (figure 11e). The contribution of the Tyrrhenian Sea is negligible and consequently this value can be considered as the transport of the newly formed WMDW flowing southwards. This local MOF allows us to diagnose well the western part of the MTHC. The depth of the maximum overturning is about $1000 \mathrm{~m}$ and we found significant transport down to $2500 \mathrm{~m}$. Figure $12 \mathrm{~d}$ shows strong interannual variability of the western $\mathrm{MOF}$ at $40^{\circ} \mathrm{N}$ (sections $\mathrm{A}+\mathrm{C}$ ). A value higher than $0.8 \mathrm{~Sv}$ is reached once during the 140 years of the simulation and the 2099 fitted value is equal to $0.43 \mathrm{~Sv}$.

In conclusion, we have proved that OPAMED8 is able to produce a strong, realistic and stable THC for the Mediterranean Sea: this is true for the heat and salt content 
(equivalent to $<\mathrm{T}>$ and $<\mathrm{S}>$ as explained above), the geography of winter mixing areas, the maximum mixed layer depth, the water mass formation rate and the deep circulation strength. These validating results allow us to have confidence in studying the possible evolution of the MTHC under IPCC-A2 scenario forcings using this model.

\section{Results of the climate change scenario}

\subsection{Air-sea fluxes}

Table 3 summarizes the difference between MC and MS for the surface fluxes for the whole Mediterranean Sea and for the water mass formation basins. In addition to the heat, water and buoyancy fluxes validated in the previous sections, this table contains the yearly and winter averaged value of the wind stress norm (called $\tau$ in the following) and of the positive part of wind stress curl (called $\xi$ in the following). These terms are important in preconditioning the deep water formation (Madec et al. 1990; Madec et al. 1996; Marshall and Schott 1999): a cyclonic curl over an area leads to Ekman pumping and isopycnal doming in this area which weakens the vertical stratification. Moreover, wind stress implies an input of turbulent kinetic energy in the mixed layer and so an increase of its depth which is another deep mixing preconditioning mechanism. Changes in these two terms may have a strong influence on the deep water formation processes in the future climate.

For the whole Mediterranean Sea, the surface heat loss decreases from $6.2 \mathrm{~W} / \mathrm{m}^{2}$ to $2.4 \mathrm{~W} / \mathrm{m}^{2}$ and the water loss (or salt gain) increases from $0.72 \mathrm{~m} /$ year to $1.01 \mathrm{~m} /$ year (2099 fitted values). These results were expected because the Mediterranean climate is known to generally become dryer and warmer in an IPCC-A2 scenario (IPCC 2001; Gibelin and Déqué 2003). The temporal evolution of the heat and water fluxes of MC 
and MS are compared in the figures 2 and 3. The rate of change of the exponential fit is equal to $-2.5 \% / y e a r$ for the heat flux and $+1.25 \% / y e a r$ for the water flux. The positive rate of change means that the water flux exponentially diverges from the control value following an unstable behaviour. For the heat flux, the negative rate of change means a saturated behaviour. Note that the interannual variability of the two terms does not change significantly between MC and MS. With regards to the buoyancy, the water flux change cancels out the heat flux change (see table 3) and no significant change in the buoyancy flux is observed $(+3 \%)$. We are therefore not able to answer the question of the evolution of the MTHC from this global approach. Looking at the $\tau$ and $\xi$ values averaged over the whole basin we note that $\tau$ decreases by $15 \%$ and $\xi$ does not change significantly. This could weaken the deep water formation preconditioning even if a sub-basin analysis is needed in case of a strong spatial variability. It is worth noting that the winterly $\tau$ does not follow exactly the same response as its yearly average with a non-significant decrease.

Focusing on the different sub-basins (Gulf of Lions, Levantine Basin, Adriatic Sea, Aegean Sea), table 3 shows that the yearly mean heat loss decreases in the Gulf of Lions and in the Levantine Basin whereas it increases significantly in the Aegean Sea and the Adriatic Sea $(+88 \%$ and $+45 \%$ respectively). The surface water loss increases everywhere. This last feature is particularly interesting for the Adriatic Sea and the Aegean Sea in which the buoyancy flux due to the water flux leads to a surface density increase in MS instead of a density decrease as in MC. This result is mainly due to the decrease in river runoff in the scenario, the Po river for the Adriatic Sea and the Black Sea for the Aegean Sea (see table 2).

The effect of the two parts of the buoyancy flux are opposed except for in the Aegean Sea and the Adriatic Sea where the buoyancy loss increases at least by more than $90 \%$. The buoyancy loss increase of these two seas means that surface waters become 
denser in MS than in MC due to surface fluxes. This is in favour of deep convection. For the other basins, there is a significant decrease in the buoyancy loss for the Gulf of Lions and a small increase for the Levantine Basin.

Table 3 shows that the yearly average of the wind stress norm $\tau$ decreases in each sub-basin except for in the Aegean Sea where it increases. The yearly MS-MC differences could reach $20 \%$. Note that the $\tau$ changes are similar in winter than in the yearly mean apart from in the Adriatic Sea. The $\tau$ decrease in the Gulf of Lions and in the Levantine Basin means that less turbulent kinetic energy is available in the mixed layer for preconditioning a deeper mixing. The response of the positive part of the curl $\xi$ is clear only for the Adriatic Sea with a decrease by $-44 \%$ (only $-28 \%$ in winter). The MS-MC differences are weak in the other basins apart from in the Gulf of Lions. A $\xi$ decrease means a weaker positive vorticity input from the atmosphere to the ocean. Consequently, the $\tau$ and $\xi$ forcing tends to weaken the preconditioning of the classical deep convection areas (the southern Adriatic Sea, the Gulf of Lions and the Levantine Basin).

The analysis of the surface fluxes allows for some hypotheses concerning the possible evolution of the winter deep convection. For the Gulf of Lions, all the surface forcings (buoyancy flux, wind stress, wind stress curl) tend to weaken the winter convection and hence the western part of the MTHC. On the contrary, the winter convection should be enhanced in the Aegean Sea with an increase of buoyancy forcing and more windy preconditioning weather. The conditions in the Levantine Basin and the Adriatic Sea have to be checked more carefully because of competing forcings.

In any case, even if the surface flux analysis is interesting, the MTHC response to climate change depends also on advection and internal mixing. So the definitive answer must be given by other diagnostics. 


\subsection{Warming and salting}

Table 4 summarizes the comparison between MC and MS in terms of SST, SSS, <T> and $\left\langle\right.$ S $>$ for the 2099 fitted values. For the SST, the mean warming is equal to $+3.1^{\circ} \mathrm{C}$ and it is quite homogeneous over the entire basin. This is probably due to the applied SST relaxation (see discussion in section 5.6). Note that the climate change response of the SST is larger than the SST bias described in section $3.2\left(+3.1^{\circ} \mathrm{C}\right.$ versus $\left.-0.8^{\circ} \mathrm{C}\right)$ and that the $3.1^{\circ} \mathrm{C}$ value is corrected for this bias. These two remarks are true for all the surface and averaged salinity and temperature characteristics and underline the key role of the control run in a climate change study.

For the SSS, the model result is more spatially heterogeneous. The basin-scale average is an increase of 0.48 psu with areas with a weaker increase (Levantine Basin: $+0.26 \mathrm{psu}$ ) and areas with a stronger increase (Adriatic Sea: +0.94 psu and Aegean Sea: $+1.03 \mathrm{psu})$. The decrease in the river runoff flux is the main cause of the behaviour of the Aegean and Adriatic Seas (see also figures $4 \mathrm{~b}$ and $4 \mathrm{c}$ ). It is worth noting that these SSS and SST changes lead to lower surface densities in MS than in MC for every sub-basin (-0.46 kg.m ${ }^{-3}$ averaged over the Mediterranean Sea). This shows that the local surface density evolution is not only driven by the local buoyancy flux, which increases in some sub-basins as seen before. The advection of lighter waters from other sub-basins and from the Atlantic Ocean also plays an important role. The Aegean Sea $\left(-0.16 \mathrm{~kg} \cdot \mathrm{m}^{-3}\right)$ and the Adriatic Sea $\left(-0.15 \mathrm{~kg} \cdot \mathrm{m}^{-3}\right)$ are the two sub-basins where the density does not decrease much. The Gulf of Lions (-0.45 kg.m ${ }^{-}$ $\left.{ }^{3}\right)$ and the Levantine Basin $\left(-0.59 \mathrm{~kg} \cdot \mathrm{m}^{-3}\right)$ show more important surface density decreases. For each sub-basin, SSS, SST and surface density changes have the same behaviour in winter as on average over the year. This leads us to conclude that deep water formation should decrease with respect to the surface density changes especially in the Gulf of Lions and in the Levantine Basin. The Adriatic Sea and the Aegean Sea 
might keep a strong local vertical circulation. This spatial discrimination is mainly due to the SSS changes driven by river runoff changes. Indeed, the change of the Evaporation-Precipitation term is spatially homogeneous (figure not shown).

Figures 5 and 6 show an exponential drift of the averaged temperature and salinity. This drift starts earlier for $\langle\mathrm{T}>$ than for $\langle\mathrm{S}>$ but with a smaller rate of change (1\%/yr versus $2 \% / y r)$. Positive rates of change means that the Mediterranean Sea has not reached its equilibrium state at the end of the $21^{\text {st }}$ century. In 2099, the changes account for $+1.5^{\circ} \mathrm{C}$ and +0.23 psu for the whole Mediterranean Sea. The changes in $<$ $\mathrm{T}>$ and $\langle\mathrm{S}>$ could also be seen as a representation of the ability of OPAMED8 to transfer the surface anomalies towards the deeper layers by vertical and horizontal physical processes (vertical mixing, subduction, diffusion, advection). For the whole Mediterranean Sea and for each sub-basin, table 4 shows areas where this transfer is more efficient (Adriatic Sea) or less efficient (Levantine Basin) than the average. This allows the following hypothesis to be formulated: during the scenario, the deeper waters of the Levantine Basin are weakly ventilated whereas the deeper layers of the Adriatic Sea seem to be strongly ventilated. This could be the signature of the weakening of either the EMDW formation by cascading or the EMDW advection. The study of the deep circulation changes between MC and MS (see below) should clarify the changes in the EMDW ventilation.

\subsection{Thermohaline circulation weakening}

The comparison between figure $7 \mathrm{a}$ and figure $7 \mathrm{~b}$ shows that the winter MLD has decreased in all the convective areas at the end of the MS run. The winter averaged MLD is only weakly modified for the Adriatic Sea and for the Aegean Sea, as expected. The Levantine Basin does not appear anymore as a specific area (MLD shallower than $200 \mathrm{~m}$ in MS). The most striking result is that the winter MLD do not 
exceed $300 \mathrm{~m}$ in the Gulf of Lions in the MS simulation whereas it was deeper than $1500 \mathrm{~m}$ in MC. We note that no other deep water formation area appears in MS.

This first qualitative aspect is confirmed by the analysis of the other MTHC diagnostics described in section 3.4. Firstly, table 6 shows that the formation rate of dense waters decreases in all the convective areas. This decrease reaches $-20 \%$ for the Gulf of Lions and for the Levantine Basin whereas it only accounts for $-10 \%$ at the global scale. Figure 10a shows for example that the decrease in the maximum formation rate is not very significant for the Mediterranean Sea. However, the most important point is the evolution of the formation density, which is the density of the peak of minimum value in the water mass transformation diagnostic (see figure $10 \mathrm{~b}$ ). In all the studied sub-basins (see table 6), the water mass formed in winter is lighter at the end of the scenario than in the control run. The difference is statistically significant for all the sub-basins. This is clear in figure $10 \mathrm{~b}$ in which the scenario fitted curve (black dashed line) goes out of the grey 95\% confidence range before 2010. The gap between the control run and the scenario is even higher for convective areas such as the Gulf of Lions, the Levantine Basin and the Aegean Sea (figures not shown). Even if the volume of the newly formed water mass does not decrease a lot between the control and the scenario, the decrease in the formation density implies that the waters formed in the scenario do not sink as deep as in the control run. The maximum density decrease occurs in the Levantine Basin with a decrease of -0.98 $\mathrm{kg} \cdot \mathrm{m}^{-3}$ between MC and MS whereas the Adriatic Sea keeps formed waters denser than $29 \mathrm{~kg} \cdot \mathrm{m}^{-3}$ in 2099.

The diagnostic of the maximum depth reached by the mixed layer every year also allows to quantify the change in the dense water formation process (see figures $8 \mathrm{a}, 8 \mathrm{~b}$, $8 \mathrm{c}$ and $8 \mathrm{~d}$ as well as table 5). These figures show that the Adriatic Sea winter convection is weakly changed. For this sea, the maximum value of the MLD does not 
change significantly as expected from the other diagnostics. For the Aegean Sea, the maximum MLD decreases by about $20 \%$ which is statistically significant at a $95 \%$ confidence level with respect to the interannual variability. The standard deviation of the maximum MLD is evaluated as $170 \mathrm{~m}$ for the Adriatic Sea and $210 \mathrm{~m}$ for the Aegean Sea in MC. This standard deviation is not significantly modified in the scenario (160m and $210 \mathrm{~m}$ respectively). For the Levantine basin, the situation is different with a strong weakening of the maximum MLD (-60\% in 2099). Figure 8a proves that this strong weakening is due to a decrease in the Levantine Deep Water formation frequency. Indeed, the LIW formation occurs yearly although reaching a shallower maximum depth. For the Levantine Basin, the new configuration without LDW formation is stable after 2020 in MS. As a signature of the termination of LDW formation, the standard deviation of the maximum MLD is strongly weakened between MC and MS, going from 520m to $260 \mathrm{~m}$. This quick evolution toward another stable state is underlined well by a high and negative rate of change of the exponential fit in figure $8 \mathrm{a}(-3.3 \% / \mathrm{yr})$.

The Gulf of Lions exhibits a similar behaviour with a rapid weakening of the frequency of the years with very deep convection events. Convection events deeper than 1000 m disappear after 2020 in our scenario. Using the MLD criterion, the Western Mediterranean deep convection weakens by $-79 \%$ in 2099 , which is statistically significant at a $95 \%$ confidence level despite the high standard deviation of the maximum MLD (590m in MC). As for the Levantine Basin, the rate of change appears to be high and negative: $-2.5 \% / \mathrm{yr}$ which corresponds to an e-folding time of 40 years.

The weakening of the winter deep water formation should have an impact on the deep branch of the MTHC. Figures 11b, 11d, 11f, 12a, 12b, 12c, 12d and table 7 show the weakening of the local overturning stream functions. 
The major conclusion is that the MTHC becomes a shallow circulation instead of a deep circulation. Indeed, intermediate waters are associated with a smaller but still important volume transport, while the deep and bottom waters become almost motionless. The westward LIW volume transport decreases by about $45 \%$ just after its formation (section F). This transport is computed as the difference between the subsurface maximum and the deep minimum of the $\mathrm{ZOF}$ at $21.7^{\circ} \mathrm{E}$ (see figure $12 \mathrm{a}$ ). We obtain a westward transport of $1.61 \mathrm{~Sv}$ in $\mathrm{MC}$ and $0.88 \mathrm{~Sv}$ in MS. We identify this transport as an index of the LIW circulation.

At the Otranto Strait, the ADW volume is nevertheless increased in MS by 37\% (see table 7 and figure 12b) but with a lower density than in MC, as seen in the formation rate diagnostic. The result is a weakening of the overturning stream function associated with the EMDW. Figures 11c, 11d show a decrease in the MOF in the northern part of the Ionian Sea. This decrease is of $-15 \%$ at $37.1^{\circ} \mathrm{N}$ (section E, table 7). Figure $11 \mathrm{~d}$ also shows that the volume transport is limited to the upper $1000 \mathrm{~m}$ in MS, while it is important up to a depth of $2500 \mathrm{~m}$ in MC. This indicates a density decrease of the water resulting from the mixing of the newly formed ADW with the northwards LIW current. This mixed water, called EMDW in present climate, is less able to cascade over the Otranto Sill in the scenario as clearly seen in figure 11d. So the EMDW transport becomes weaker and shallower. The minimum value of the ZOF at $21.7^{\circ} \mathrm{E}$ (section $\mathrm{F}$, table 7 ) is also a good index of the ventilation of the EMDW along its path towards the eastern part of the Mediterranean Sea. A decrease of $-85 \%$ is obtained in 2099. Figure $11 \mathrm{~b}$ shows that the deep negative cell of the Eastern MTHC is quite negligible in MS. We finally conclude that a large weakening of the deep Eastern Mediterranean THC occurs during our scenario. It is worth noting that Myers and Haines (2002) obtain the same ZOF pattern in a sensitivity study to changes in surface net evaporation. They so prove that a large increase or decrease in 
the net evaporation can lead to the MTHC becoming a shallow intermediate circulation overlying stagnant deep waters.

No sign of any long-term EMT-like circulation is found in our scenario even if the Aegean Sea has been identified as a potential deep water formation site through the air-sea fluxes analysis. However, figure $8 \mathrm{~d}$ shows that convection that is deeper than usual can occur in MS during some very rare winters. A study of these specific years has to be performed before a definitive conclusion about EMT-like circulation and climate change in the Mediterranean Sea can be made.

In the Western Basin (Gulf of Lions area), the situation is as sensitive as for the EMDW. The maximum of the Western MOF is equal to $0.2 \mathrm{~Sv}$ in MS (figure 11f) instead of $0.5 \mathrm{~Sv}$ in MC (figure 11e). The time series of the maximum of the MOF between Spain and Italy at $40^{\circ} \mathrm{N}$ (section $\mathrm{A}+\mathrm{C}$ in figure $4 \mathrm{a}$ ) is plotted in figure $12 \mathrm{~d}$. It is a good index of the WMDW transport from the north to the south of the Western Mediterranean and resolves its interannual variability. During the scenario, a decrease of $-74 \%$ is obtained in 2099 for the MOF maximum (rate of change equal to $2.5 \% / y r)$. This difference is statistically significant at the $95 \%$ confidence level. The standard deviation of the maximum value of the MOF is notably decreased in the scenario going from $0.16 \mathrm{~Sv}$ to $0.11 \mathrm{~Sv}$. Moreover, the $0.1 \mathrm{~Sv}$ isoline is situated at $1100 \mathrm{~m}$ in MS (figure 11f) instead of $2500 \mathrm{~m}$ in MC (figure 11e). As for the Eastern Basin, the Western MTHC is strongly weakened and becomes shallower during the scenario.

A more thorough study of the time-series should be done in future work to clarify the time lag-correlation between the different water masses transport decreases. Indeed, the following questions remain open: Is the surface flux evolution responsible for all the decreases of the water mass transport ? Or does the decrease of the LIW formation lead the weakening of the WMDW or EMDW formation? Does the weakening of the 
WMDW influence the surface circulation? These questions seem crucial for better understanding and perhaps monitoring the response of the Mediterranean water masses to climate change. These issues would also allow us to assess and understand the current climate temporal variability of the Mediterranean water mass formation. In conclusion, the impact of an IPCC-A2 climate change scenario on the MTHC circulation seems to be a shallowing of the main deep water masses and a weakening of their transport. This weakening reaches $80 \%$ for the deep circulation and leads to almost motionless water masses below $1000 \mathrm{~m}$ in the eastern and the western basins.

\section{Discussion}

\subsection{The Gibraltar Strait}

The impact of the Mediterranean Sea on the Atlantic Ocean occurs by the means of the Strait of Gibraltar (Reid 1979, Curry et al. 2003; Potter and Lozier 2004). A modification of the T-S characteristics of the Mediterranean Outflow Water (MOW) could modify the heat and salt content of the Atlantic Ocean (Curry et al. 2003) and influence its thermohaline circulation.

The present climate steady state is the following: the Mediterranean Sea releases heat and freshwater to the atmosphere and the Atlantic Ocean supplies the same amount of heat and freshwater to the Mediterranean Sea through the Gibraltar Strait. These Gibraltar net transports are the result of a warm and fresh surface inflow of the Atlantic Waters (AW) and of a cold and salty deep outflow of the Mediterranean Outflow Waters (MOW). With the rigid lid hypothesis, water fluxes are converted into salt fluxes but the results are equivalent. So, if we consider the Gibraltar net transports, the Mediterranean Sea is a salt source and a heat sink for the Atlantic Ocean. However, if we only consider the Atlantic at intermediate depths, the MOW 
(stabilises at about $1000 \mathrm{~m}$ in the Atlantic) is a heat and salt source because at this depth, the Atlantic water masses are fresher and colder.

We would like to underline that our model has not been designed to study the response of the MOW to the climate change. Indeed, in our model, the evolution of the MOW is not completely free because of the 3D relaxation in the buffer zone. The imposed temperature and salinity anomalies of the buffer zone used for the relaxation come from the global low resolution AOGCM (see section 2) and no feedback is allowed from the ORCM towards these anomalies (one-way nesting strategy). Our strategy also obliges us to neglect the following feedback loop: the MOW modification influences the Atlantic Ocean at intermediate depths, the Atlantic SST is modified by mixing and finally this SST modification has a feedback on the Mediterranean Sea through atmospheric teleconnections or Atlantic Waters flowing into the Mediterranean Sea. Because of our downscaling strategy, the results concerning the MOW have to be considered with care. However, due to their likely important impact on the Atlantic Ocean and despite the short period studied (100 years) compared to the Atlantic time scale, we would like to present them.

Despite the weakening by the intermediate MTHC, the Gibraltar Strait exchanges do not change much with a 4\% difference between MC (1.17 Sv) and MS (1.12 Sv) for the volume transport in 2099 (fitted value).

At the Gibraltar Strait in 2099, the yearly averaged surface temperature of the Atlantic inflow is equal to $18.0^{\circ} \mathrm{C}$ in $\mathrm{MC}$ and to $20.1^{\circ} \mathrm{C}$ in $\mathrm{MS}$. Despite the weakening of the Gibraltar volume transport, this temperature difference implies that the associated heat inflow (inflow for the Mediterranean Sea) becomes higher in MS than in MC (8.2 $10^{13} \mathrm{~W}$ for MS in averaged over $2099,+11 \%$ ). In addition, the MOW temperature increases from $12.3^{\circ} \mathrm{C}$ in $\mathrm{MC}$ to $14.8^{\circ} \mathrm{C}$ in $\mathrm{MS}$ and the MOW heat transport (outflow) strongly increases $\left(7.010^{13} \mathrm{~W}\right.$ for $\mathrm{MS}$ in $\left.2099,+19 \%\right)$. These competing heat 
transports lead to a decrease of the net heat transport across the Gibraltar Strait towards the Mediterranean Sea between the control run $\left(1.510^{13} \mathrm{~W}\right.$ in 2099) and the scenario $\left(1.210^{13} \mathrm{~W},-19 \%\right)$. If we integrate the heat gain difference over the 20002099 period, the Mediterranean Sea total heat gain through the Gibraltar Strait decreases by $5.910^{21} \mathrm{~J}$ over the 100 -year period $\left(-13 \%\right.$ i.e. $-1.510^{6} \mathrm{~J} / \mathrm{m}^{3}$ with respect to the Mediterranean Sea volume). This is in accordance with the basin averaged surface heat loss which decreases between MC and MS (see section 4.1). However, the decrease in the surface heat loss is more important than the decrease in the Gibraltar heat gain and, consequently, the Mediterranean Sea warms up as shown by the $<\mathrm{T}>$ variable (see section 4.2 ).

In terms of salinity, the AW salinity and the MOW salinity increase, from 36.32 to $36.52 \mathrm{psu}$ and from 38.35 to 38.80 psu respectively. The $4 \%$ weakening of the Gibraltar volume transport cancels out the salinity increases and leads to a decrease of salt transports (-4\% for the AW and $-4 \%$ for the MOW) in contrast with the response of temperature. Finally, the net salt transport (outflow - inflow) increases between MC $\left(2.310^{9} \mathrm{~g} / \mathrm{s}\right.$ in 2099$)$ and MS $\left(2.510^{9} \mathrm{~g} / \mathrm{s}\right.$ in $\left.2099,+9 \%\right)$. Integrated over the 20002099 period, the conclusion is the same and the Mediterranean salt loss through the Gibraltar Strait slightly increases by $+3.510^{17} \mathrm{~g}$ of salt over the 100 -year period. This means an increase by $5 \%$ with respect to the MC value $\left(7.210^{18} \mathrm{~g}\right.$ of salt integrated over the 100-year period). During the scenario, the net evaporation (E-P-R) increases (see section 4.1) leading to a more saline Mediterranean Sea. The compensation which occurs at the Gibraltar Strait is too weak to reach a balance and so the Mediterranean Sea continues to become increasingly salty as seen on the salt content evolution $(<\mathrm{S}>$ variable, section 4.2).

With regards to the impact of the changes occurring in the Mediterranean Sea on the Atlantic Ocean, we can conclude that the MOW could be warming (with an average 
rate of $+0.24^{\circ} \mathrm{C} /$ decade $)$ and getting saltier $(+0.045 \mathrm{psu} /$ decade $)$ than in present-day climate. These trends seem to be already observed in the Atlantic (Curry et al. 2003; Potter and Lozier 2004). Potter and Lozier (2004) give comparable values for the observed trends since 1955: $+0.101 \pm 0.024^{\circ} \mathrm{C} /$ decade and $+0.0283 \pm 0.0067$ $\mathrm{psu} / \mathrm{dec}$ de. In this context, the $21^{\text {st }}$ century would see an acceleration of the already observed trends.

However, for the heat and salt budget of the Atlantic at intermediate depths, the important point is that the MOW outflow heat transport could increase, while the outflow salt transport could decrease. The integrated MS-MC difference over the 2000-2099 period indicates that the Mediterranean Sea could transport less salt (-4.1 $10^{18} \mathrm{~g}$ of salt over the 100 -year period) and more heat $\left(+1.510^{22} \mathrm{~J}\right.$ over the 100 -year period) into the Atlantic Ocean at intermediate depths over the $21^{\text {st }}$ century if the climate system follows the IPCC-A2 scenario instead of keeping the present state.

\subsection{Uncertainties}

In the current study, we did not explore the uncertainties linked to climate change scenarios. As mentioned in the European PRUDENCE project (Prediction of Regional scenarios and Uncertainties for Defining EuropeaN Climate change risks and Effects, Christensen et al. 2002), many sources of uncertainties are related to the projection of regional climate changes. To improve the confidence level of our results, other IPCC scenarios and other atmospheric forcings should be tested.

In the context of global warming, many authors have also shown that the Atlantic THC response is sensitive to the choice of the ocean model (parameterizations, resolution, complexity), to the $\mathrm{CO}_{2}$ emission rate and to the THC initial state (Stocker and Schmittner 1997; Manabe and Stouffer 1999; IPCC 2001). It is likely that the situation could be the same for the Mediterranean Sea THC. We therefore think that ensemble simulations are needed for assessing in detail the possible evolution of the 
Mediterranean THC for the $21^{\text {st }}$ century. Testing different ocean models and different physical parameterizations is also necessary in the future.

\subsubsection{Sensitivity to the physical parameterizations}

A good example of uncertainty due to the ocean model is the choice of the physical parameterizations (vertical diffusion, horizontal diffusion, convection). In our study, we use the 1.5 turbulent closure scheme available in OPA8.1 for the vertical eddy diffusivity (Blanke and Delecluse 1993) and the vertical diffusion is enhanced in case of unstable stratification to simulate the convection process. Chanut (2003) proved that a high resolution version of OPA using these schemes is able to simulate well deep convection and water mass formation in the Labrador Sea. The use of a KPP scheme does not significantly improve the simulation. Moreover, the enhanced vertical diffusion parameterization is used in many OGCMs and is known to represent well the water mass formation process, as noted by Klinger et al. (1996). For the WMDW formation and with OPA, Madec et al. (1991a) also proved that the deep convection is not very sensitive to the choice of the coefficient of vertical diffusion.

However, we believe that these choices may have an impact on the MTHC response to climate change. The present study is a first assessment of the possible response of the MTHC to climate change. Consequently, various sensitivity studies are needed in the future to determine the robustness of our results.

For example, other schemes of vertical diffusion and convection have been used in recent Mediterranean modelling studies dealing with water mass formation (e.g. Mellor-Yamada 2.5-order turbulence closure scheme in Nittis et al. 2003; fixed value for viscosity coefficient and fixed profile for diffusivity coefficient in Rupolo et al. 2003; constant value in Myers and Haines 2002 for the diffusion but with a complete convection scheme). The choice of the horizontal diffusion coefficient has also to be 
tested as the WMDW formation process seems to be very sensitive to its choice (Madec et al. 1991a, 1991b). Moreover, more complex deep convection parameterizations could be also used as the GISS model described in Canuto et al. (2004) in a study dealing with the Labrador Sea deep convection. The authors show that the GISS vertical mixing model avoids the shortcomings of both Mellor-Yamada 2.5 and KPP models when it is implemented into a coarse resolution OGCM.

\subsubsection{Sensitivity to the diagnostic methods}

To diagnose the mixed layer depth in an ocean model is far from being objective. In the present study, a TKE criterion based on a fixed threshold for the vertical eddy diffusivity $\left(5 \mathrm{~cm}^{2} \cdot \mathrm{s}^{-1}\right)$ has been used. Other fixed values could be used, as well as other criteria, such as those based on the vertical stability with a fixed density gap. The impact of those criteria on the mixed layer depth is difficult to assess as it depends on the basin and on the depth reached by the convection. For the Gulf of Lions, tests have been performed with a criterion based on the density vertical profile (fixed value $0.05 \mathrm{~kg} \cdot \mathrm{m}^{-3}$ ). Between the two criteria, we obtain an error of about $30 \%$ for the mixed layer depth values given in section 3.4. This lack of consistency is a problem even if it probably comes from the density criterion which has not been fitted for the Mediterranean Sea. However, the main goal of our study is to assess the MLD response due to the climate change (see section 4.3). For the MS-MC values given in section 4.3, we obtain an error bar of 5\%. Thus, we can conclude that the uncertainties of the MS-MC analysis due to the choice of the MLD diagnostic are relatively small.

\subsubsection{River runoff impact}

In the scenario, the spatial heterogeneity of the evolution of the SSS field is mainly driven by the decrease in runoff of the rivers of southern Europe. This heterogeneity plays a major role in influencing the spatial pattern of the MTHC weakening. 
Nevertheless, the river runoff is known to be very difficult to reproduce using a GCM (Douville et al., 2002) even with a $50 \mathrm{~km}$ resolution (Hagemann et al., 2004). Moreover, in an ensemble of IPCC-A2 regional simulations, it has been proved during the European PRUDENCE project (Christensen et al., 2002) that rivers show a broad range of responses to the climate change in different regional climate models (Hagemann, personal communication). This confirms again the need for ensemble simulations for which we could use river flux anomalies coming from various regional climate models. For this purpose, the role of our Black Sea/Aegean Sea exchanges parameterization should not be underestimated. Indeed, this parameterization integrates the uncertainties related to the model water flux over the Black Sea plus the precipitation over the Black Sea catchment basin.

Moreover, we would like to underline that all the results presented in this work have been obtained with a rigid lid model. We are aware of the problems due to the use of a virtual salt flux instead of a freshwater flux at the surface (Huang 1993). A free surface version of OPA may be used in future work (Roullet and Madec 2000).

\subsubsection{Impact of the SST relaxation}

In a forced ocean model with SST relaxation, the model SST is mainly driven by the damping SST which has to be known a priori. In our scenario, we use a low resolution AOGCM scenario to create the damping SST anomalies. The use of this constraint assumes that the Mediterranean SST large-scale response to the climate change is comparable in OPAMED8 and in the low resolution ocean model of the AOGCM. This hypothesis is probably true to first order. However, the feedback of an Atlantic THC change on the SST and then on the climate has been proved by many authors (e.g. Vellinga and Wood 2002). We think that this feedback should also exist for the Mediterranean Sea at a smaller scale. Particularly, we think that locally the 
regional pattern of the MTHC weakening could have a negative feedback to the SST warming and so to the regional climate. This feedback will be taken into account in future work with a high resolution Mediterranean-atmosphere coupled model developed at CNRM (Sevault et al. 2002; Somot 2005).

\section{Conclusion}

We performed a realistic scenario of what could be the evolution of the Mediterranean Sea under the IPCC-A2 scenario hypotheses during the $21^{\text {st }}$ century. The various forcings (air-sea fluxes, river runoff fluxes and Atlantic-Mediterranean exchanges) have been computed using previously run AOGCM and ARCM. For the whole Mediterranean Sea, the heat loss by the surface decreases from 6.2 to $2.4 \mathrm{~W} . \mathrm{m}^{-2}$ and the water loss (or salt gain) increases from 0.72 to $1.01 \mathrm{~m} /$ year. The wind stress forcing also decreases in the sub-basins studied except for in the Aegean Sea.

An increase in SST, which is nearly spatially homogeneous in distribution, $\left(+3.1^{\circ} \mathrm{C}\right.$ in 2099, value obtained with an exponential fit) is obtained, while a heterogeneous SSS increase is produced by the model (from $+0.26 \mathrm{psu}$ in the Levantine Basin to +1.03 psu in the Aegean Sea). The pattern of SSS anomalies is mainly driven by the river runoff decrease, especially by the Po and the Black Sea behaviour.

These competing changes nevertheless lead to a decrease in the surface density and thus a weakening of the Mediterranean thermohaline circulation except for in the Adriatic Sea which maintains a strong deep water formation. This weakening is evaluated at about $80 \%$ for the deep circulation (WMDW, EMDW) and at $40 \%$ for the intermediate circulation (LIW) from the maximum values of the overturning stream functions. In the Adriatic Sea, the formation of the ADW is enhanced but the cascading of this water past the Otranto Strait, then becoming the EMDW, is notably 
less efficient in the scenario. Similarly, the LDW is not formed anymore in the Levantine Basin in the scenario. No EMT-like event is observed even though the surface flux change over the Aegean Sea should favour deep water formation in this basin.

The anomalies of SST and SSS are transmitted into the deeper layers. This transmission is more efficient in the shallow sub-basins, which keep a vertical THC (Adriatic Sea, Aegean Sea), than in the deeper sub-basins (Levantine Basin, Gulf of Lions area). Over the whole Mediterranean Sea, the averaged temperature increases by $1.5^{\circ} \mathrm{C}$ and the averaged salinity by $0.23 \mathrm{psu}$.

The Mediterranean Sea evolution also has an impact on the Mediterranean Outflow Waters (MOW) characteristics. During the scenario, these waters become warmer and saltier $\left(+2.5^{\circ} \mathrm{C}\right.$ and $+0.45 \mathrm{psu}$ in 2099$)$. Warming and salting of the Mediterranean deep waters and of the MOW have been reported from hydrographic data for recent decades and might be already a Mediterranean Sea climate change signature.

In this study, we have used a control run of the same length as the scenario to evaluate a possible drift of our model. The stability of this run as well as the weak biases shown by the OPAMED8 model gives us some confidence in the scenario results. Nevertheless ensemble simulations are needed to assess the robustness of our results.

\section{Acknowledgments}

This work was supported by the European Union Program Energy, Environment and Sustainable Development under contract EVK2-2001-00156 (PRUDENCE) and by the GICC-MedWater program of the Ministère de l'Ecologie et du Développement Durable (French Environment Ministry). We also thank Dr. Michel Crépon, Dr Bernard Barnier and Dr Gurvan Madec for helpful comments and suggestions. 


\section{References}

Arakawa A (1972) Design of UCLA general circulation model. University of California, n. 7, $116 \mathrm{pp}$

Artegiani A, Bregant D, Paschini E, Pinardi N, Raicich F, Russo A (1997) The Adriatic Sea general circulation. Part I: air-sea interactions and water mass structure. J Phys Oceanogr 27:1492-1514

Barnier B, Siefridt L, Marchesiello P (1995) Thermal forcing for a global ocean circulation model using a three year climatology of ECMWF analyses. J Mar Syst 6 (4):363-380

Béranger K, Mortier L, Gasparini G, Gervasio L, Astraldi M, Crépon M (2004) The dynamic of the Sicily Strait: A comprehensive study from observations and models. Deep-Sea Res II 51(4-5):411-440

Béthoux JP (1979) Budgets of the Mediterranean Sea. Their dependence on the local climate and on the characteristics of the Atlantic waters. Oceanologica Acta $2: 157-163$

Béthoux JP, Gentili B, Raunet J, Tailliez D (1990) Warming trend in the western Mediterranean deep water. Nature 347:660-662

Béthoux JP (1993) Mediterranean sapropel formation, dynamic and climatic viewpoints. Oceanologica Acta 16:127-133

Béthoux JP, Gentili B, Tailliez D (1998) Warming and freshwater budget change in the Mediterranean since the 1940s, their possible relation to the greenhouse effect. Geophys Res Lett 25(7):1023-1026 
Blanke B, Delecluse P (1993) Variability of the tropical Atlantic ocean simulated by a general circulation model with two different mixed layer physics. J Phys Oceanogr 23:1363-1388

Brankart J and Pinardi N (2001) Abrupt cooling of the Mediterranean Levantine Intermediate Water at the Beginning of the 1980s: Observational Evidence and Model Simulation. J Phys Oceanogr 31:2307-2320

Bryden H, Kinder T (1991) Steady two-layer exchange through the Strait of Gibraltar. Deep-Sea Research 38:S445-S463

Bunker A, Charnock H, Goldsmith R (1982) A note on the heat balance of the Mediterranean and Red Seas. J Mar Res 40:73-84

Canuto V, Howard A, Hogan P, Cheng Y, Dubovikov M and Montenegro L (2004) Modeling ocean convection. Ocean Modelling 7:75-95

Castellari S, Pinardi N, Leaman K (2000) Simulation of the water mass formation processes in the Mediterranean Sea: Influence of the time frequency of the atmospheric forcing. J Geophys Research, 105(C10):24,157-24,181

Chanut J (2003) Paramétrisation de la restratification après convection profonde en mer du Labrador. PhD thesis, Université Joseph Fourier, Grenoble, 185 pp (in French)

Christensen JH, Carter TR, Giorgi F (2002) PRUDENCE employs new methods to assess European climate change. EOS 83:147

Cubasch U, Waszkewitz J, Hegerl G, Perlwitz J (1995) Regional climate changes as simulated in time-slice experiments. Clim Change 31:273-304

Curry R, Dickson B, Yashayaev I (2003) A change in the freshwater balance of the Atlantic Ocean over the past four decades. Nature 426(6968):826-828 
da Silva A, Young C, Levitus S (1994) Atlas of surface marine data. Algorithms and Procedure, NOAA Atlas Ser., 1, 74 pp., Natl Oceanic and Atmos Admin, Silver Spring, Md

Déqué M, Dreveton C, Braun A, Cariolle D (1994) The ARPEGE-IFS atmosphere model: a contribution to the French community climate modelling. Clim Dyn 10:249-266.

Déqué M and Piedelievre JP (1995) High-Resolution climate simulation over Europe. Clim Dyn 11:321-339

Döös K, Meier M, Döscher R (2004) The Baltic haline conveyor belt or the overturning circulation and micing in the Baltic. Ambio 33(4-5):261-266

Douville H, Planton S, Royer JF, Stephenson DB, Tyteca S, Kergoat L, Lafont S, Betts RA (2000) The importance of vegetation feedbacks in doubled-CO2 timeslice experiments. J Geophys Res 105:14841-14861

Douville H, Chauvin F, Royer JF, Salas-Mélia D, Tyteca S (2002) Sensitivity of the hydrological cycle to increasing amounts of greenhouse gases and aerosols. Clim Dyn. 20:45-68

Drillet Y, Bourdallé-Badie R, Siefridt L, Le Provost C (2005) The MEDDIES in the Mercator North Atlantic and Mediterranean Sea eddy-resolving model. J Geophys Res 110(C03016), doi:10.1029/2003JC002170

Frei C, Christensen JH, Déqué M, Jacob D, Jones RG, Vidale PL (2003). Daily precipitation statistics in regional climate models: evaluation and intercomparison for the European Alps. J. Geophys. Res. 108: ACL 91-19

Fuda JL, Etiope G, Millot C, Favali P, Calcara M, Smirglio G, Boschi E (2002) Warming, salting and origin of the Tyrrhenian Deep Water. Geo Res Lett 29(19) 
Garrett C (1996) The role of the strait of Gibraltar in the evolution of the Mediterranean water, poperties and circulation. Bulletin de l'Institut Océanographique de Monaco 17:1-19

Gibelin AL and Déqué M (2003) Anthropogenic climate change over the Mediterranean region simulated by a global variable resolution model. Climate Dynamics 20:327-339

Gibson JK, Kållberg P, Uppala S, Hernandez A, Serano E (1997) ERA description. ECMWF Re-analysis project report series. ECMWF, Shinfield Park, Reading, RG2 9AX, UK

Gilman C and Garrett C (1994) Heat flux parameterizations for the Mediterranean Sea: the role of atmospheric aerosols and constraints from the water budget. J Geophys Research 99:5119-5134

Giorgi F and Mearns LO (1999) Regional climate modeling revisited. An introduction to the special issue. J Geophys Res 104:6335-6352

Hagemann S, Machenhauer B, Jones RG, Christensen OB, Déqué M, Jacob D, Vidale PL (2004) Evaluation of water and energy budgets in regional climate models applied over Europe. Clim Dyn, 23:547-567

Huang RX (1993) Real freshwater flux as a natural boundary condition for the salinity balance and thermohaline circulation forced by evaporation and precipitation. J Phys Oceano 23:2428-2446

IPCC (2001) Climate Change 2001. The scientific basis. Contribution of Working Group I to the third assessment report of the IPCC. Houghton, Ding, Griggs, Noguer, Van der Linder, Dai, Maskell, Johnson (Eds). Cambridge University Press, Cambridge, UK. 881 pp 
Jackett DR and McDougall TJ (1995) Minimal adjustment of hydrographic data to achieve static stability. J Atmos Ocean Tech 12:381-389

Josey S, Kent E, Taylor P (1999) New insights into the ocean heat budget closure problem from analysis of the SOC air-sea flux climatology. J Clim 12:2,8562,880

Josey S (2003) Changes in the heat and freshwater forcing of the eastern Mediterranean and their influence on deep water formation. J Geophys Research $108(\mathrm{C} 7)$

Kistler R et al. (2001) The NCEP-NCAR 50-year reanalysis: Monthly means CDROM and documentation. Bull Am Meteorol Soc. 82:247-267

Klein B, Roether W, Manca B, Bregant D, Beitzel V, Kovacevic V, Luchetta A (1999) The large deep water transient in the Eastern Mediterranean. Deep Sea Res Part I 46:371-414

Klein B, Roether W, Kress N, Manca B, Ribera D'Alcala M, Souvermezoglou E, Theocharis A, Civitarese G, Luchetta A (2003) Accelarated oxygen consumption in eastern Mediterranean deep waters following the recent changes in thermohaline circulation. J Geophys Res 108(C9)

Klinger, Marshall J, Send U (1996) Representation of convective plumes by vertical adjustment. J Geophys Res 101:18175-18182

Korres G, Pinardi N, Lascaratos A (2000) The ocean response to low frequency interannual atmospheric variability in the Mediterranean sea. Part I: Sensitivity experiments and energy analysis. J Climate 13:705-731

Lascaratos A (1993) Estimation of deep and intermediate water mass formation rates in the Mediterranean Sea. Deep-Sea Res II 40(6):1327-1332 
Lascaratos A, Williams R, Tragou E (1993) A mixed-layer study of the formation of Levantine Intermediate Water. J Geophys Res 98:14,739-14,749

Lascaratos A, Roether W, Nittis K, Klein B (1999) Recent changes in deep water formation and spreading in the Eastern Mediterranean Sea: A review. Prog Oceanogr 44:5-36

Macdonald A, Candela J, Bryden H (1994) An estimate of the net heat transport through the Strait of Gibraltar. Seasonal and Interannual Variability of the Western Mediterranean Sea, P.E. La Violette, Ed., Coastal Estuarine Studies, 46, Amer. Geophys. Union 13-32

Machenhauer B, Windelband M, Botzet M, Christensen JH, Déqué M, Jones J, Ruti PM, Visconti G (1998) Validation and analysis of regional present-day climate and climate change simulations over Europe. MPI Report No 275, MPI, Hamburg, Germany, 87 pp

Madec G (1990) La formation d'eau profonde et son impact sur la circulation régionale en Méditerranée occidentale : une approche numérique. $\mathrm{PhD}$ thesis, Université Paris VI, 193 pp (in french)

Madec G, Chartier M, Crépon M (1991a) The effect of thermohaline forcing variability on deep water formation in the western Mediterranean sea : a high resolution three dimensional numerical study. Dyn Atmos Ocean 15:301-332

Madec G, Chartier M, Delecluse P, Crépon M (1991b) A three dimensional numerical study of deep water formation in the northwestern Mediterranean sea. J Phys Oceanogr 21(9):1349-1371

Madec G, Lott F, Delecluse P, Crépon M (1996) Large-scale preconditioning of deepwater formation in the northwestern Mediterranean sea. J Phys Oceanogr 26:1393-1408 
Madec G, Delecluse P, Imbard M, Levy C (1998) OPA 8.1, Ocean General Circulation Model, Reference Manual. IPSL/LODYC, France, Note du Pôle de modélisation, 11

Manabe S and Stouffer R (1999) The role of the thermohaline circulation in climate. Tellus 51:91-109

Manca B, Budillon G, Scarazzato P, Ursella L (2003) Evolution of dynamics in the eastern Mediterranean affecting water mass structures and properties in the Ionian and Adriatic Seas. J Geophys Res 108(C9)

Marshall J and Schott F (1999) Open-ocean convection: observations, theory, and models. Rev Geophys 37:1-64

Matthiesen S and Haines K (2003) A hydraulic box study of the Mediterranean response to postglacial sea level rise. Paleooceano 18(4)

MEDAR/MEDATLAS Group (2002) MEDAR/MEDATLAS 2002 Database. Cruise inventory, observed and analyzed data of temperature and bio-chemical parameters, 4 Cdrom

MEDOC Group (1970) Observations of formation of deep-water in the Mediterranean Sea. Nature 227:1037-1040

Mertens C and Schott F (1998) Interannual variability of deep-water formation in the Northwestern Mediterranean. J Phys Oceanogr 28:1410-1424

Myers P, Haines K, Rohling E (1998) Modeling the paleocirculation of the Mediterranean: The last glacial maximum and the holocene with emphasis on the formation of sapropel S1. Paleooceano 13(6):586-606

Myers P and Haines K (2000) Seasonal and Interannual Variability in a Model of the Mediterranean under derived Flux Forcing. J Phys Oceanogr 30:1069-1082 
Myers P and Haines K (2002) Stability of the Mediterranean's thermohaline circulation under modified surface evaporative fluxes. J Geophys Res 107(C3), doi:10.1029/2000JC000550

New M, Hulme M, Jones PD (1999) Representing twentieth century space-time climate variability. Part 1: development of a 1961-90 mean monthly terrestrial climatology. J Climate 12:829-856

Nittis K., Lascaratos A., Theocharis A. (2003) Dense water formation in the Aegean Sea: numerical simulations during the Eastern Mediterranean Transient. J Geophys Res 108(C9), doi:10.1029/2002JC001352

Ozsoy E, Hecht A, Unluata U, Brenner S, Sur H, Bishop J, Latif M, Rozentraub Z, Oguz T (1993) A synthesis of the Levantine basin circulation and hydrography, 1985-1990. Deep Sea Res, Part II 40:1075-1119

Pickard G and Emery W (1994) Descriptive Physical Oceanography: An Introduction. Pergamon Press, New-York, $5^{\text {th }}$ edition

Potter R and Lozier S (2004) On the warming and salinification of the Mediterranean outflow waters in the North Atlantic. Geophys Res Lett 31:L01202, doi:10.1029/2003GL018161

Reid, J.L. (1979) On the contribution of the Mediterranean Sea outflow to the Norwegian-Greenland Sea. Deep-Sea Res., Part A 26:1199-1223

Reynaud T, LeGrand P, Mercier H, Barnier B (1998) A new analysis of hydrographic data in the Atlantic and its application to an inverse modeling study. International WOCE Newsletters 32:29-31

Roether W, Manca B, Klein B, Bregant D, Georgopoulos D, Beitzel W, Kovacevic V, Luchetta A (1996) Recent changes in Eastern Mediterranean Deep Waters. Science 271:333-334 
Rohling E and Bryden H (1992) Man-Induced Salinity and Temperature Increases in Western Mediterranean Deep Water. J Geophys Res 97 (C7):11191-11198

Roullet G and Madec G (2000) Salt conservation, free surface, and varying levels: a new formulation for ocean general circulation models. J Geophys Res 105 23927-23942

Royer JF, Cariolle D, Chauvin F, Déqué M, Douville H, Planton S, Rascol A, Ricard JL, Salas y Melia D, Sevault F, Simon P, Somot S, Tyteca S, Terray L, Valcke S (2002) Simulation of climate changes during the 21-st century including stratospheric ozone. Géosciences 334 (3):147-154

Rupolo V., Marullo S., Iudicone D. (2003) Eastern Mediterranean Transient studied with Lagrangian diagnostics applied to a Mediterranean OGCM forced by satellite SST and ECMWF wind stress for the years 1988-1993. J Geophys Res 108 (C9) 8121, doi:10.1029/2002JC001403

Schott F, Visbeck M, Send U, Fisher J, Stramma L, Desaubies Y (1996) Observations of deep convection in the Gulf of Lions, northern Mediterranean, during the winter of 1991/1992. J Phys Oceanogr 26:505-524

Sevault F, Somot S, Déqué M (2002) Couplage ARPEGE-MEDIAS - OPAMEDITERANEE. Les étapes, Note de Centre, CNRM, GMGEC, n. 84 (in french, available at samuel.somot@meteo.fr)

Smith T, Reynolds R, Livezey R, Stokes D (1996) Reconstruction of historical sea surface temperatures using empirical orthogonal functions. J Climate 9:14031420

Smith W and Sandwell D (1997) Global sea floor topography from satellite altimetry and ship depth sounding. Sciences 277 (5334): 1956-1962 
Somot (2005) Modélisation climatique du bassin méditerranéen : variabilité et scénarios de changement climatique. PhD thesis, Univ. Paul Sabatier, Toulouse, France, 333 pp.

Somot S and Sevault F (2005) Climate change impact on the Mediterranean Sea circulation: a regional modelling approach. Note de Centre du CNRM, GMGEC 95, internal report (available at samuel.somot@meteo.fr)

Speer K and Tziperman E (1992) Rates of water mass formation in the North Atlantic Ocean. J Phys Oceanogr 22:93-104

Stanev E, Le Traon P-Y, Peneva E (2000) Sea level variations and their dependency on meteorological and hydrological forcing: Analysis of altimeter and surface data for the Black Sea. J Geophys Res (105) C7:17203-17216

Stocker T and Schmittner A (1997) Influence of $\mathrm{CO}_{2}$ emission rates on the stability of the thermohaline circulation. Nature 388:862-865

Stratford K and Haines K (2000) Frictional sinking of the dense water overflow in a z-coordinate OGCM of the Mediterranean Sea. Geophys Res Lett 27(24):39693972

Thorpe RB and Bigg GR (2000) Modelling the sensitivity of Mediterranean Outflow to anthropogenically forced climate change. Clim. Dyn. 16:355-368

Tziperman E (1986) On the role of interior mixing and air-sea fluxes in determining the stratification and circulation of the oceans. J Phys Oceanogr 16:680-693

Tziperman E and Speer K (1994) A study of water mass transformation in the Mediterranean Sea: analysis of climatological data and a simple three-box model. Dynamics of Atmosphere and Oceans 21:53-82

Valcke S, Terray L, Piacentini A (2000) OASIS 2.4 Ocean Atmosphere Sea Ice Soil, User's Guide, CERFACS 
Vellinga M and Wood R (2002) Global climatic impacts of a collapse of the Atlantic thermohaline circulation. Climatic Change 54(3):251-267

Vörösmarty C, Fekete B, Tucker B (1996) Global river discharge database, RivDis, vol. 0 to 7. International Hydrological Program, Global Hydrological Archive and Analysis Systems, UNESCO, Paris, France

Walin G (1982) On the relation between sea-surface heat flow and the thermal circulation in the ocean. Tellus 34:187-195

Wilby RL, Wigley TML, Conway D, Jones PD, Hewitson BC, Main J, Wilks DS (1998) Statistical downscaling of general circulation model output: A comparison of methods. Water Resources Research 34:2995-3008

Wu P and Haines K (1996) Modelling the dipersal of Levantine Intermediate Water and its role in Mediterranean deep water formation. J Geophys Res 101:65916607

Wu P and Haines K (1998) The general circulation of the Mediterranean Sea from a 100-year simulation. J Geophys Res 103 (C1):1121-1135

Wüst G (1961) On the vertical circulation of the Mediterranean Sea. J Geophys res $66(10): 3261-3271$ 


\section{Figures Captions}

Fig. 1: Simple diagram of the downscaling strategy explaining the forcing links between the three models (AOGCM, ARCM, ORCM) used in the study

Fig. 2: Time series of the net surface heat flux (in $\mathrm{W} / \mathrm{m}^{2}$ ) integrated over the whole Mediterranean Sea and yearly averaged. In grey, the control run (MC) and in black, the scenario (MS). A linear fit has been computed for MC (grey dashed line) whereas an exponential fit describes MS (black dashed line). The values are the slope of the linear fit for MC and the rate of change (in \% per year) of the exponential fit for MS. A range corresponding to a 95\% confidence level (in grey) has been added for the fitted curve of MC

Fig. 3: As for fig. 2, but for the net surface water flux including the river runoff flux (E-P-R, in mm/day)

Fig. 4: Sea surface salinity in winter (January, February, March) (a) for an observed climatology (MEDATLAS-II), (b) for the 2070-2099 average of the present-climate or control simulation (MC) performed with OPAMED8, and (c) for the future-climate simulation or scenario (MS). The Gulf of Lions area is defined by sections A $\left(40^{\circ} \mathrm{N}\right)$ and $\mathrm{B}\left(9.5^{\circ} \mathrm{E}\right)$; the Adriatic Sea by section $\mathrm{D}\left(40^{\circ} \mathrm{N}\right)$; the Levantine Basin by section I $\left(24.9^{\circ} \mathrm{E}\right)$ and $\mathrm{H}$; the Aegean Sea by sections $\mathrm{G}$ and H. Sections $\mathrm{A}+\mathrm{C}, \mathrm{D}, \mathrm{E}$ and $\mathrm{F}$ are used to compute the local values of the overturning stream functions

Fig. 5: As for fig. 2, but for the 3D averaged temperature, $\langle\mathrm{T}\rangle$, of the Mediterranean Sea expressed in ${ }^{\circ} \mathrm{C}$

Fig. 6: As for fig. 2, but for the 3D averaged salinity, $\langle\mathrm{S}\rangle$, of the Mediterranean Sea expressed in psu

Fig 7: Mixed layer depth (in meters, interval=50m) for the winter season (JFM) averaged over the 2070-2099 period (a) for the control run (MC), and (b) for the scenario (MS) 
Fig 8: As for fig. 2, but for the maximum depth reached by the monthly mean mixed layer depth (1 point per year - in meters) (a) for the Levantine Basin, (b) for the Adriatic Sea, (c) for the Gulf of Lions area, and (d) for the Aegean Sea

Fig 9: Water mass formation rate (in Sv) as a function of density. Values are computed for the entire Mediterranean and are averaged over the 2070-2099 period. In grey, the control run (MC) and in black, the scenario (MS). In dotted line, the heat flux contribution and in dashed line the salt flux contribution

Fig 10: As for fig. 2, but for (a) the yearly maximum values of the water mass formation rate in $\mathrm{Sv}$ (this maximum formation rate corresponds to the minimum of the curve of the figure 9 computed every year for the entire Mediterranean) and (b) the density for which the maximum formation rate occurs

Fig 11: Vertical sections averaged over the 2070-2099 period for global Mediterranean Zonal Overturning stream Function (a) for the control run, and (b) for the scenario. The same calculation has been done for the Adriatic Meridional Overturning stream Function covering the Adriatic Sea plus the northern part of the Ionian Sea limited to $37^{\circ} \mathrm{N}$ (c) for the control run, and (d) for the scenario. The western Mediterranean Meridional Overturning stream Function limited to $38^{\circ} \mathrm{N}$ has also been computed (e) for the control run, and (f) for the scenario

Fig 12: As for fig. 2, but for optimum values of the zonal or meridional overturning stream functions calculated for the sections defined in figure $4 \mathrm{a}$, (a) for the section $\mathrm{F}$ at $21.7^{\circ} \mathrm{E}$ between the Ionian Sea and the Levantine Basin (the intermediate maximum and the deep minimum are plotted on the same figure), (b) for the section $\mathrm{D}$ at $40^{\circ} \mathrm{N}$ (Otranto Strait), (c) for the section E at $37.1^{\circ} \mathrm{N}$ (northern part of the Ionian Sea), and (d) for the sections $\mathrm{A}+\mathrm{C}$ at $40^{\circ} \mathrm{N}$ (western Mediterranean) 


\section{Table Captions}

Tab. 1: Characteristics of the different simulations used in this study, AS for Atmosphere Scenario, MC for Mediterranean Control run and MS for Mediterranean Scenario (we use obs for observations and ano for anomalies).

Tab. 2: Yearly mean river runoff fluxes (in $\mathrm{m}^{3} / \mathrm{s}$ ) applied to the Mediterranean Sea model during each decade of the scenario (MS run) for the main rivers and the Black Sea. The decades are named by the first year, 2010 for the 2010-2019 decade for example. The climatology (clim) is applied for the 1960-1999 period of the scenario and for the control run.

Tab. 3: Air-sea fluxes for the year 2099 in the control run (MC) and in the scenario (MS). Values are obtained by means of a linear fit for MC and an exponential fit for MS performed on the 1960-2099 time series of each variable. Values are spatially averaged over the sub-basins defined in figure $4 \mathrm{a}$. For the buoyancy flux, the terms due to heat flux and to water flux are indicated in brackets. For $\tau$ (wind stress norm) and $\xi$ (positive part of the wind stress curl), the winter averaged values are in brackets. A MC value noted * means that the slope of the linear fit is statistically different from zero with a $95 \%$ significance level. A MS value noted * means that the MS-MC difference in 2099 is statistically significant with a 95\% significance level.

Tab. 4: SST (in ${ }^{\circ} \mathrm{C}$ ), 3D averaged temperature $\left(<\mathrm{T}>\right.$ in $\left.{ }^{\circ} \mathrm{C}\right)$, SSS (in psu) and 3D averaged salinity $(<S>$ in psu) for the year 2099 in the control run (MC) and in the scenario (MS). Values are obtained by means of a linear fit for MC and an exponential fit for MS performed on the 1960-2099 time series of each variable. Values are spatially averaged over the sub-basins defined in figure $4 \mathrm{a}$. The equivalent values for the MEDATLAS-II database (MEDAR/MEDATLAS Group, 2002) and the RSST (in brackets, Smith et al. 1996) are named OBS for observations. A MC value noted $*$ means that the slope of the linear fit is statistically different from zero with a 
95\% significance level. A MS value noted * means that the MS-MC difference in 2099 is statistically significant with a $95 \%$ significance level.

Tab. 5: Maximum mixed layer depth (in $\mathrm{m}$ ) for the year 2099 in the control run (MC) and in the scenario (MS) for each sub-basins defined in figure 4a. Values are obtained by means of a linear fit for MC and an exponential fit for MS performed on the 19602099 time series of each variable. Maximum values are calculated using monthly mean MLD files. A MC value noted * means that the slope of the linear fit is statistically different from zero with a $95 \%$ significance level. A MS value noted * means that the MS-MC difference in 2099 is statistically significant with a $95 \%$ significance level.

Tab. 6: Formation rate (in Sv) and formation density (in $\mathrm{kg} / \mathrm{m}^{3}$ ) for the year 2099 in the control run (MC) and in the scenario (MS). Values are obtained by means of a linear fit for MC and an exponential fit for MS performed on the 1960-2099 time evolution of each variable. Values are spatially averaged over the sub-basins defined in figure 4a. A MC value noted * means that the slope of the linear fit is statistically different from zero with a $95 \%$ significance level. A MS value noted * means that the MS-MC difference in 2099 is statistically significant with a 95\% significance level.

Tab. 7: Maximum and minimum values of overturning stream functions (in $\mathrm{Sv}$ ) for the year 2099 in the control run (MC) and in the scenario (MS). Values are obtained by means of a linear fit for MC and an exponential fit for MS performed on the 19602099 time series of each variable. Values are calculated over sections defined in figure 4a. A MC value noted * means that the slope of the linear fit is statistically different from zero with a $95 \%$ significance level. A MS value noted * means that the MS-MC difference in 2099 is statistically significant with a 95\% significance level. 


\begin{tabular}{|c|c|c|c|}
\hline simulations & AS & MC & MS \\
\hline models & ARPEGE & OPAMED8 & OPAMED8 \\
\hline years & $1960-2099$ & $1960-2099$ & $1960-2099$ \\
\hline resolution (Med. Sea) & $50 \mathrm{~km}$ & $10 \mathrm{~km}$ & $10 \mathrm{~km}$ \\
\hline control / scenario & Scenario from 2000 & control & Scenario from 2000 \\
\hline GHG and aerosols & obs then IPCC-A2 & - & - \\
\hline Air-sea fluxes & - & $1960-1980$ AS & $1960-2099$ AS \\
\hline SST & obs then obs + AOGCM ano & obs & obs + AOGCM ano \\
\hline runoff & - & obs & obs + AS ano \\
\hline buffer zone & - & obs & obs + AOGCM ano \\
\hline
\end{tabular}

Tab. 1: Characteristics of the different simulations used in this study, AS for Atmosphere Scenario, MC for Mediterranean Control run and MS for Mediterranean Scenario (we use obs for observations and ano for anomalies)

\begin{tabular}{|c|c|c|c|c|c|c|c|c|c|c|c|}
\hline Rivers & clim & $\mathbf{2 0 0 0}$ & $\mathbf{2 0 1 0}$ & $\mathbf{2 0 2 0}$ & $\mathbf{2 0 3 0}$ & $\mathbf{2 0 4 0}$ & $\mathbf{2 0 5 0}$ & $\mathbf{2 0 6 0}$ & $\mathbf{2 0 7 0}$ & $\mathbf{2 0 8 0}$ & $\mathbf{2 0 9 0}$ \\
\hline Rhone & 1700 & 1666 & 1615 & 1649 & 1581 & 1564 & 1530 & 1513 & 1462 & 1377 & 1360 \\
\hline Po & 1498 & 1378 & 1288 & 1258 & 1183 & 1228 & 1228 & 1183 & 1183 & 1183 & 1213 \\
\hline Ebre & 428 & 398 & 321 & 343 & 321 & 317 & 309 & 274 & 274 & 197 & 188 \\
\hline Nile & 875 & 945 & 954 & 962 & 910 & 928 & 823 & 875 & 858 & 901 & 814 \\
\hline Black Sea & 8036 & 6911 & 6027 & 5625 & 4902 & 4420 & 4661 & 4581 & 4018 & 2893 & 2330 \\
\hline
\end{tabular}

Tab. 2: Yearly mean river runoff fluxes (in $\mathrm{m}^{3} / \mathrm{s}$ ) applied to the Mediterranean Sea model during each decade of the scenario (MS run) for the main rivers and the Black Sea. The decades are named by the first year, 2010 for the 2010-2019 decade for example. The climatology (clim) is applied for the 1960-1999 period of the scenario and for the control run. 


\begin{tabular}{|c|c|c|c|c|c|}
\hline \multirow{2}{*}{$\begin{array}{l}\text { Basin } \\
\text { Flux }\end{array}$} & \multicolumn{5}{|c|}{ Mediterranean Sea } \\
\hline & $\underset{W / m^{2}}{Q t o t}$ & $\begin{array}{l}E-P-R \\
m m / d\end{array}$ & $\begin{array}{c}\text { Buoy (heat+water) } \\
10^{-9} \mathrm{~m}^{2} \cdot \mathrm{s}^{-3}\end{array}$ & $\begin{array}{l}\tau(J F M) \\
10^{-2} N / m^{2}\end{array}$ & $\begin{array}{l}\xi_{10^{-7}}(\mathrm{NFM}) \\
\mathrm{m}^{3}\end{array}$ \\
\hline $\mathrm{MC}$ & -6.2 & $2.0(0.72 \mathrm{~m} / \mathrm{y})$ & $-10.2(-3.1 /-7.1)$ & $3.3(6.2)$ & $1.4(2.4)$ \\
\hline MS & $-2.4 *$ & $2.8(1.01 \mathrm{~m} / \mathrm{y}) *$ & $-10.5(-1.2 * /-9.7 *)$ & $2.8 *(6.0)$ & $1.5(2.6)$ \\
\hline Basin & \multicolumn{5}{|c|}{ Gulf of Lions } \\
\hline $\mathrm{MC}$ & -22.0 & 1.6 & $-16.6(-11.0 /-5.6)$ & $5.3(9.5)$ & $2.5(3.8)$ \\
\hline MS & $-14.1 *$ & $2.2 *$ & $-13.7 *(-7.0 * /-7.8 *)$ & $4.2 *(8.4 *)$ & $2.4(4.4 *)$ \\
\hline Basin & \multicolumn{5}{|c|}{ Levantine Basin } \\
\hline $\mathrm{MC}$ & -2.1 & 2.8 & $-10.8(-1.0 /-9.8)$ & $3.4(5.4)$ & $1.4(2.4)$ \\
\hline MS & $-0.2 *$ & $3.4 *$ & $-12.6(-0.1 /-12.1 *)$ & $2.8 *(5.3)$ & $1.4(2.6)$ \\
\hline Basin & \multicolumn{5}{|c|}{ Adriatic Sea } \\
\hline $\mathrm{MC}$ & -16.5 & -0.2 & $-8.0(-8.2 /+0.2)$ & $1.8(3.2)$ & $4.1(5.4)$ \\
\hline MS & $-23.9 *$ & $0.8 *$ & $-15.2 *(-12.0 * /-3.4 *)$ & $1.6 *(4.1 *)$ & $2.3 *(3.8 *)$ \\
\hline Basin & \multicolumn{5}{|c|}{ Aegean Sea } \\
\hline $\mathrm{MC}$ & -21.6 & -1.3 & $-10.4(-10.8 /+0.4)$ & $4.0(4.9)$ & $2.9(3.4)$ \\
\hline MS & $-40.6 *$ & $2.5 *$ & $-29.4 *(-20.3 * /-9.5 *)$ & $5.0 *(7.6 *)$ & $2.8(3.4)$ \\
\hline
\end{tabular}

Tab. 3: Air-sea fluxes for the year 2099 in the control run (MC) and in the scenario (MS). Values are obtained by means of a linear fit for MC and an exponential fit for MS performed on the 1960-2099 time series of each variable. Values are spatially averaged over the sub-basins defined in figure 4a. For the buoyancy flux, the terms due to heat flux and to water flux are indicated in brackets. For $\tau$ (wind stress norm) and $\xi$ (positive part of the wind stress curl), the winter averaged values are in brackets. A MC value noted * means that the slope of the linear fit is statistically different from zero with a $95 \%$ significance level. A MS value noted * means that the MS-MC difference in 2099 is statistically significant with a 95\% significance level. 


\begin{tabular}{|c|c|c|c|c|}
\hline Basin & \multicolumn{4}{|c|}{ Mediterranean Sea } \\
\hline${ }^{\circ}$ Corpsu & $S S T$ & $<T>$ & $S S S$ & $\langle S\rangle$ \\
\hline OBS & $19.7(19.5)$ & 13.7 & 38.16 & 38.62 \\
\hline $\mathrm{MC}$ & 18.7 & $13.2 *$ & 38.18 & $38.62 *$ \\
\hline MS & $21.8 *$ & $14.7 *$ & $38.66 *$ & $38.85 *$ \\
\hline Basin & \multicolumn{4}{|c|}{ Gulf of Lions } \\
\hline OBS & $17.7(17.5)$ & 13.0 & 37.90 & 38.41 \\
\hline $\mathrm{MC}$ & 16.8 & $12.4 *$ & 37.98 & $38.31 *$ \\
\hline MS & $19.9 *$ & $14.0 *$ & $38.42 *$ & $38.56 *$ \\
\hline Basin & \multicolumn{4}{|c|}{ Levantine Basin } \\
\hline OBS & $21.4(21.0)$ & 14.0 & 39.06 & 38.77 \\
\hline $\mathrm{MC}$ & 20.1 & $13.6 *$ & 39.04 & $38.85 *$ \\
\hline MS & $23.3 *$ & $14.9 *$ & $39.30 *$ & $38.95 *$ \\
\hline Basin & \multicolumn{4}{|c|}{ Adriatic Sea } \\
\hline OBS & $17.7(17.9)$ & 13.8 & 37.76 & 38.57 \\
\hline $\mathrm{MC}$ & 16.9 & 13.0 & 38.44 & 38.60 \\
\hline MS & $20.4 *$ & $16.7 *$ & $39.38 *$ & $39.40 *$ \\
\hline Basin & \multicolumn{4}{|c|}{ Aegean Sea } \\
\hline OBS & $18.9(18.7)$ & 14.8 & 38.32 & 38.88 \\
\hline $\mathrm{MC}$ & 17.9 & 13.9 & 38.46 & 38.86 \\
\hline MS & $21.3 *$ & $16.6 *$ & $39.49 *$ & $39.27 *$ \\
\hline
\end{tabular}

Tab. 4: SST (in ${ }^{\circ} \mathrm{C}$ ), 3D averaged temperature $\left(<\mathrm{T}>\right.$ in ${ }^{\circ} \mathrm{C}$ ), SSS (in psu) and 3D averaged salinity $(<\mathrm{S}>$ in psu) for the year 2099 in the control run $(\mathrm{MC})$ and in the scenario (MS). Values are obtained by means of a linear fit for MC and an exponential fit for MS performed on the 1960-2099 time series of each variable. Values are spatially averaged over the sub-basins defined in figure $4 \mathrm{a}$. The equivalent values for the MEDATLAS-II database (MEDAR/MEDATLAS Group, 2002) and the RSST (in brackets, Smith et al. 1996) are named OBS for observations. A MC value noted $*$ means that the slope of the linear fit is statistically different from zero with a 95\% significance level. A MS value noted * means that the MS-MC difference in 2099 is statistically significant with a 95\% significance level. 


\begin{tabular}{|c|c|c|c|c|}
\hline & \multicolumn{4}{|c|}{ Maximum mixed layer depth in winter (in m) } \\
\hline basins & Gulf of Lions & Adriatic Sea & Levantine Basin & Aegean Sea \\
\hline MC & 2170 & 800 & 680 & 750 \\
\hline MS & $460 *$ & 850 & $270 *$ & $610 *$ \\
\hline
\end{tabular}

Tab. 5: Maximum mixed layer depth (in $\mathrm{m}$ ) for the year 2099 in the control run (MC) and in the scenario (MS) for each sub-basins defined in figure 4a. Values are obtained by means of a linear fit for MC and an exponential fit for MS performed on the 19602099 time series of each variable. Maximum values are calculated using monthly mean MLD files. A MC value noted * means that the slope of the linear fit is statistically different from zero with a $95 \%$ significance level. A MS value noted * means that the MS-MC difference in 2099 is statistically significant with a $95 \%$ significance level.

\begin{tabular}{|c|c|c|c|c|c|}
\hline & \multicolumn{5}{|c|}{ Formation rate (in Sv) / Density $\left(\mathbf{k g} / \mathbf{m}^{\mathbf{3}}\right)$} \\
\hline basins & Gulf of Lions & Adriatic Sea & Levantine Basin & Aegean Sea & Mediterranean \\
\hline MC & 0.93 & 0.54 & 1.34 & 1.04 & 4.01 \\
\hline MS & $0.74 *$ & 0.50 & $1.07 *$ & 0.99 & $3.59 *$ \\
\hline & \multicolumn{5}{|c|}{ Formation density $\left(\mathbf{k g} / \mathbf{m}^{\mathbf{3}}\right)$} \\
\hline MC & 28.91 & 29.23 & 29.05 & 29.19 & 28.89 \\
\hline MS & $28.60 *$ & $29.01 *$ & $28.07 *$ & $28.71 *$ & $28.57 *$ \\
\hline
\end{tabular}

Tab. 6: Formation rate (in Sv) and formation density (in $\mathrm{kg} / \mathrm{m}^{3}$ ) for the year 2099 in the control run (MC) and in the scenario (MS). Values are obtained by means of a linear fit for MC and an exponential fit for MS performed on the 1960-2099 time evolution of each variable. Values are spatially averaged over the sub-basins defined in figure 4a. A MC value noted * means that the slope of the linear fit is statistically different from zero with a $95 \%$ significance level. A MS value noted * means that the MS-MC difference in 2099 is statistically significant with a 95\% significance level. 


\begin{tabular}{|c|c|c|c|c|}
\hline & \multicolumn{4}{|c|}{ Overturning stream function (in Sv) } \\
\hline sections & Section $\boldsymbol{A}+\boldsymbol{C}\left(\mathbf{4 0}^{\circ} \mathbf{N}\right)$ & Section $\mathbf{D}\left(\mathbf{4 0}^{\circ} \mathbf{N}\right)$ & Section $\boldsymbol{E}\left(\mathbf{3 7 . 1}^{\circ} \mathbf{N}\right)$ & Section $\boldsymbol{F}\left(\mathbf{2 1 . 7 ^ { \circ }} \mathbf{N}\right)$ \\
\hline MC & 0.43 & 0.46 & 0.68 & $1.01 /-0.60$ \\
\hline MS & $0.11 *$ & $0.63 *$ & 0.58 & $0.79 * /-0.09 *$ \\
\hline
\end{tabular}

Tab. 7: Maximum and minimum values of overturning stream functions (in $\mathrm{Sv}$ ) for the year 2099 in the control run (MC) and in the scenario (MS). Values are obtained by means of a linear fit for MC and an exponential fit for MS performed on the 19602099 time series of each variable. Values are calculated over sections defined in figure 4a. A MC value noted * means that the slope of the linear fit is statistically different from zero with a $95 \%$ significance level. A MS value noted * means that the MS-MC difference in 2099 is statistically significant with a 95\% significance level. 


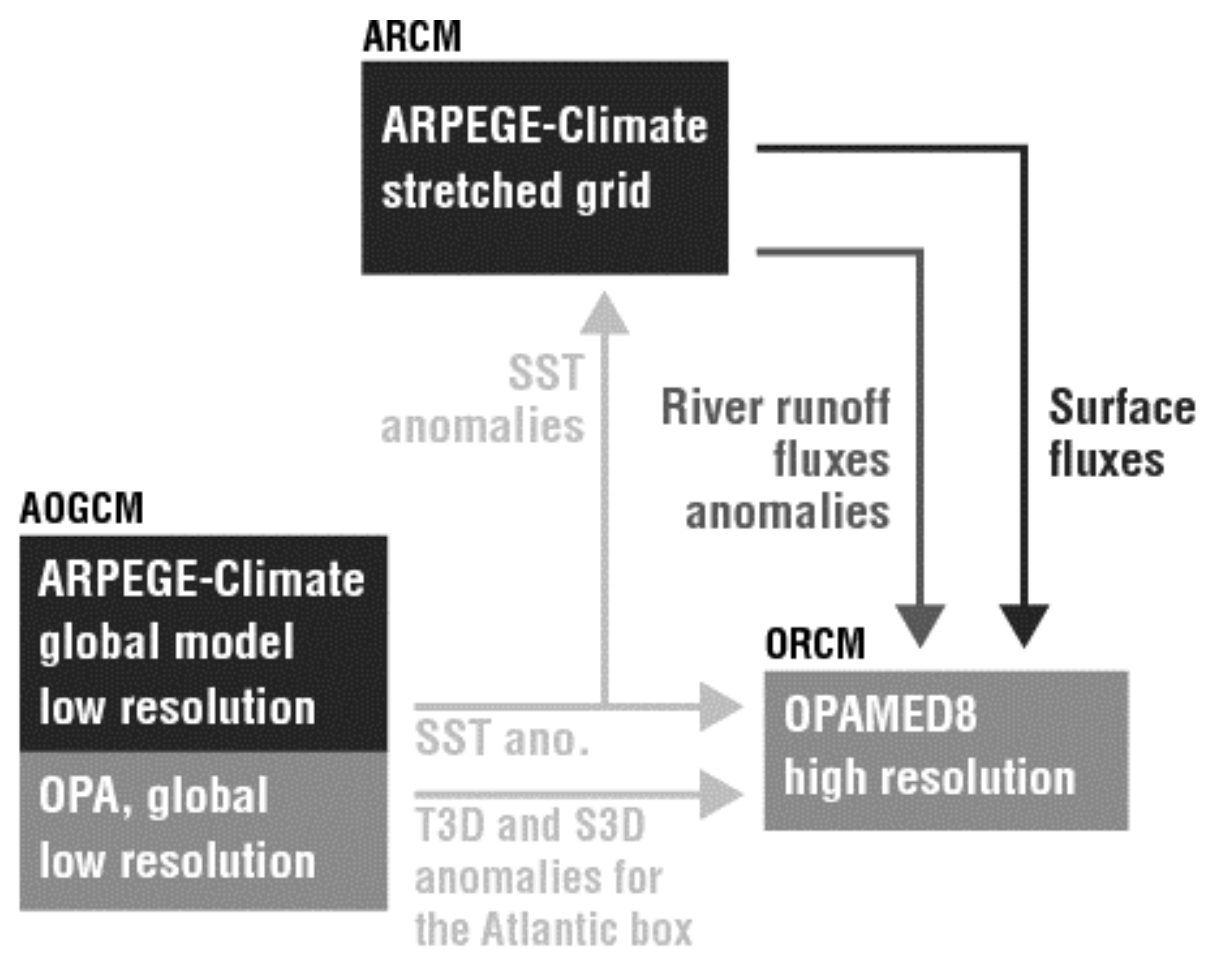

Fig. 1: Simple diagram of the downscaling strategy explaining the forcing links between the three models (AOGCM, ARCM, ORCM) used in the study 


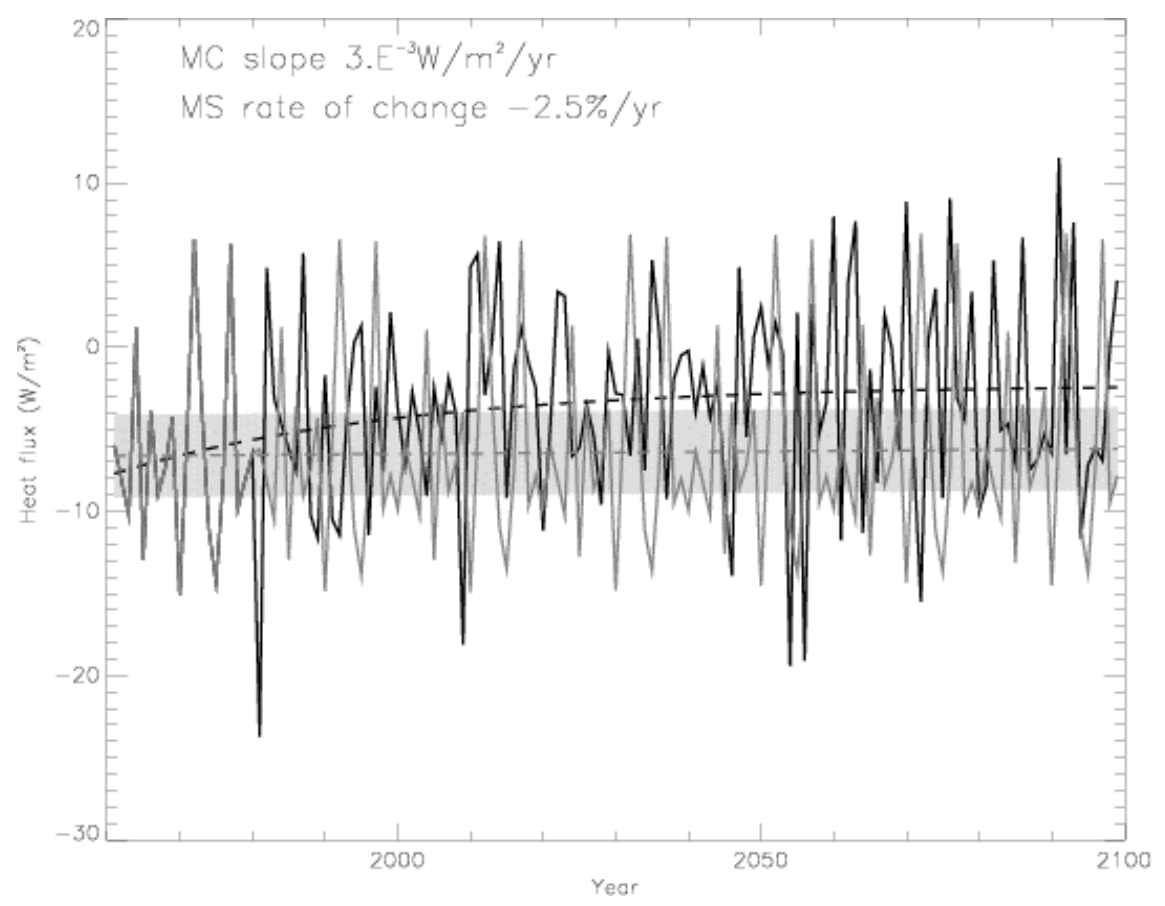

Fig. 2: Time series of the net surface heat flux (in $\mathrm{W} / \mathrm{m}^{2}$ ) integrated over the whole Mediterranean Sea and yearly averaged. In grey, the control run (MC) and in black, the scenario (MS). A linear fit has been computed for MC (grey dashed line) whereas an exponential fit describes MS (black dashed line). The values are the slope of the linear fit for MC and the rate of change (in \% per year) of the exponential fit for MS. A range corresponding to a $95 \%$ confidence level (in grey) has been added for the fitted curve of MC

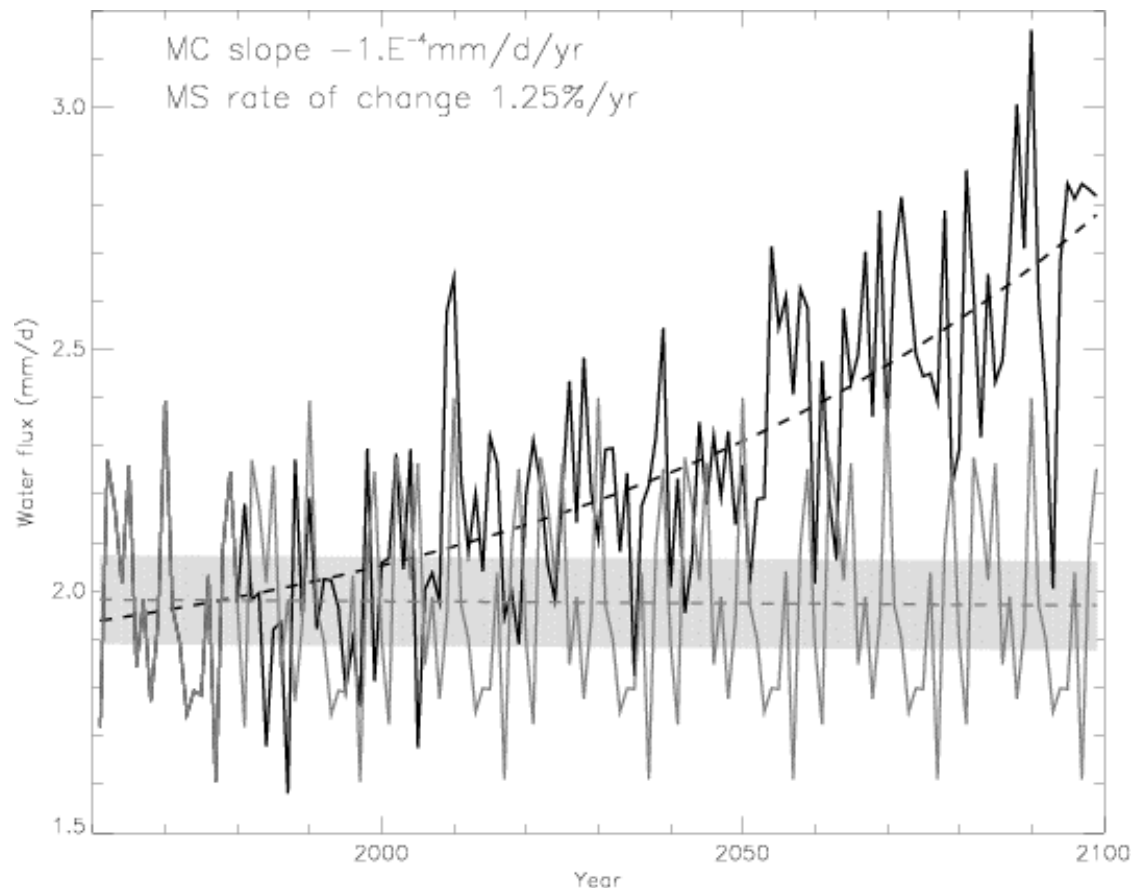

Fig. 3: As for fig. 2, but for the net surface water flux including the river runoff flux (E-P-R, in mm/day) 
(a)

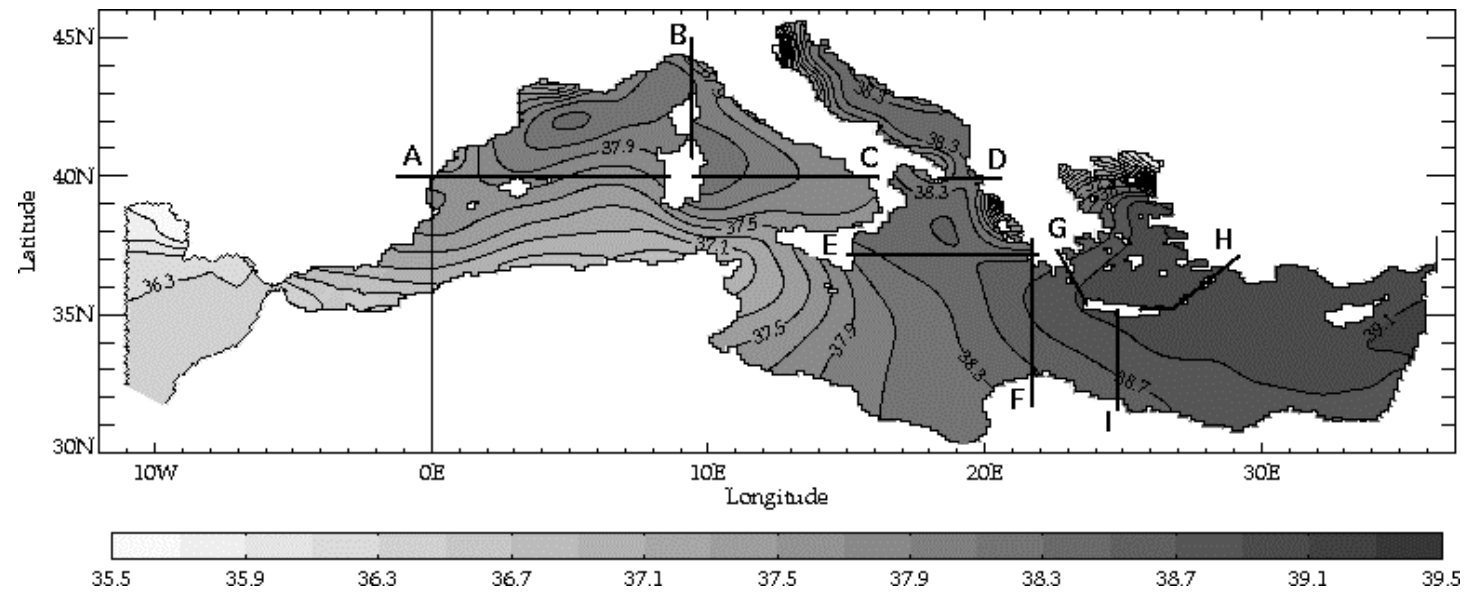

(b)

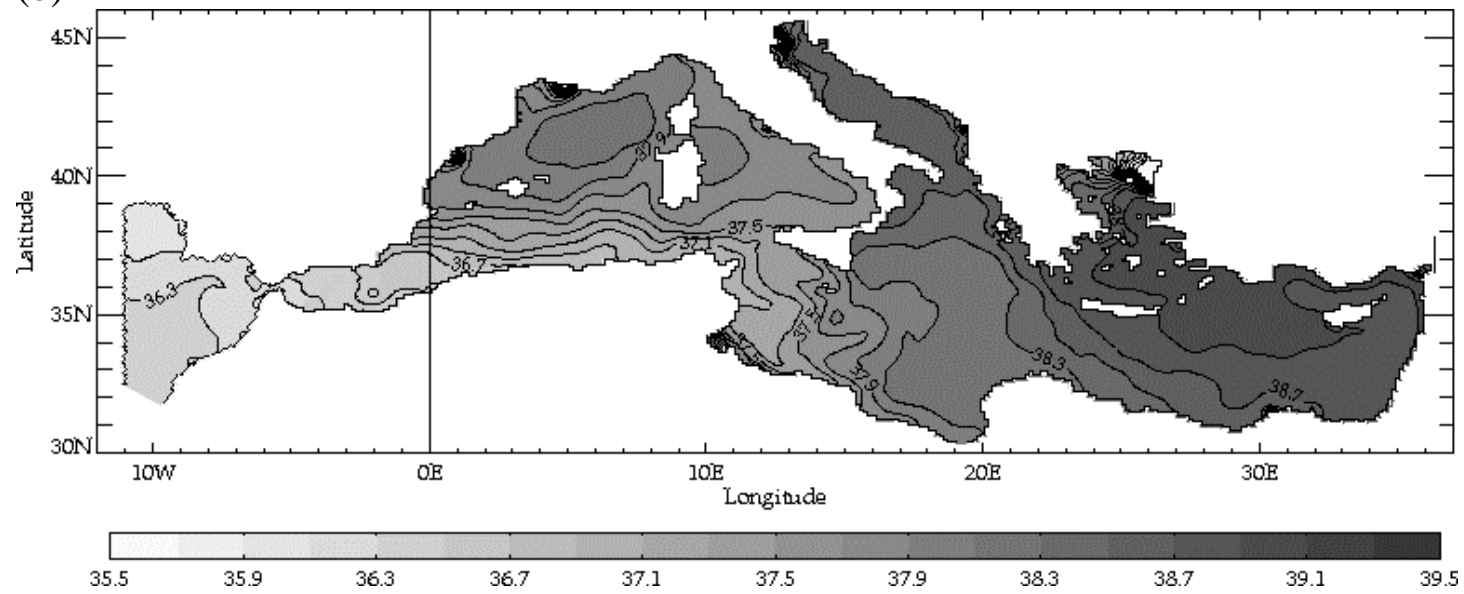

(c)

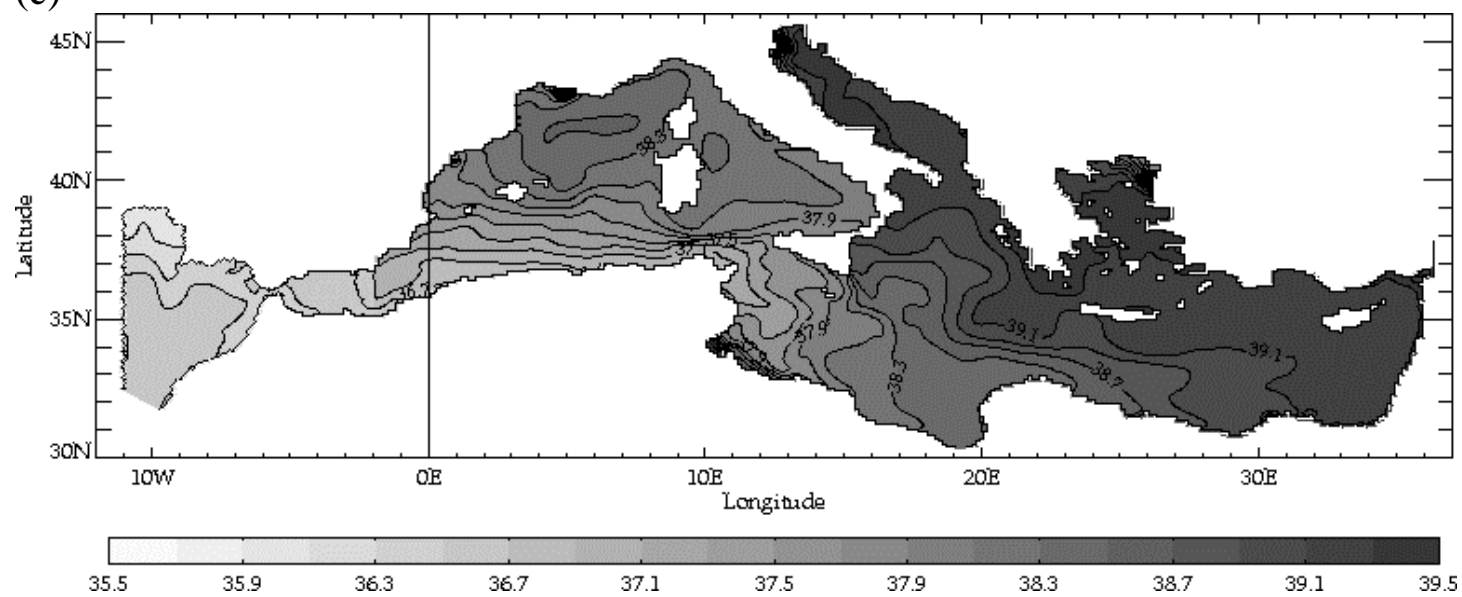

Fig. 4: Sea surface salinity in winter (January, February, March) (a) for an observed climatology (MEDATLAS-II), (b) for the 2070-2099 average of the present-climate or control simulation (MC) performed with OPAMED8, and (c) for the future-climate simulation or scenario (MS). The Gulf of Lions area is defined by sections A $\left(40^{\circ} \mathrm{N}\right)$ and $\mathrm{B}\left(9.5^{\circ} \mathrm{E}\right)$; the Adriatic Sea by section $\mathrm{D}\left(40^{\circ} \mathrm{N}\right)$; the Levantine Basin by section I $\left(24.9^{\circ} \mathrm{E}\right)$ and $\mathrm{H}$; the Aegean Sea by sections $\mathrm{G}$ and $\mathrm{H}$. Sections $\mathrm{A}+\mathrm{C}, \mathrm{D}, \mathrm{E}$ and $\mathrm{F}$ are used to compute the local values of the overturning stream functions 


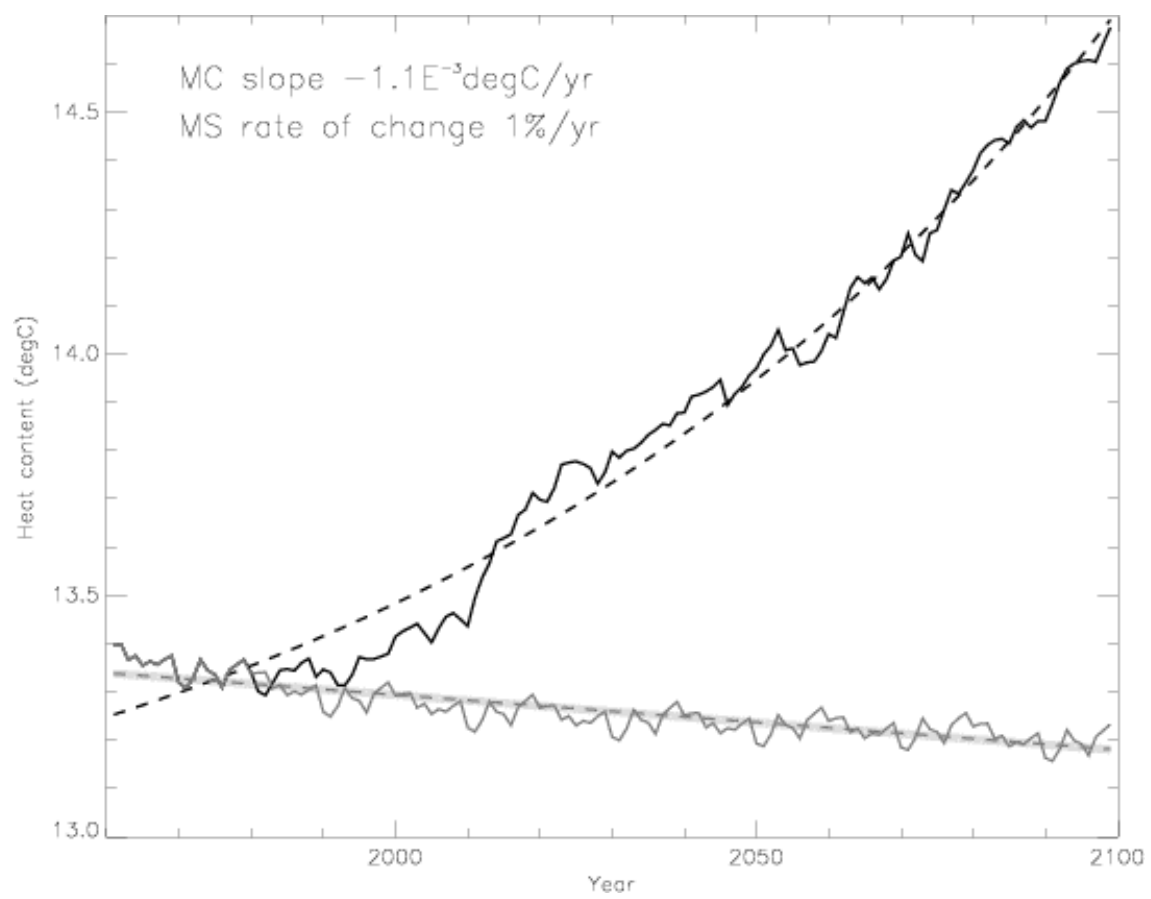

Fig. 5: As for fig. 2, but for the 3D averaged temperature, $\langle\mathrm{T}\rangle$, of the Mediterranean Sea expressed in ${ }^{\circ} \mathrm{C}$

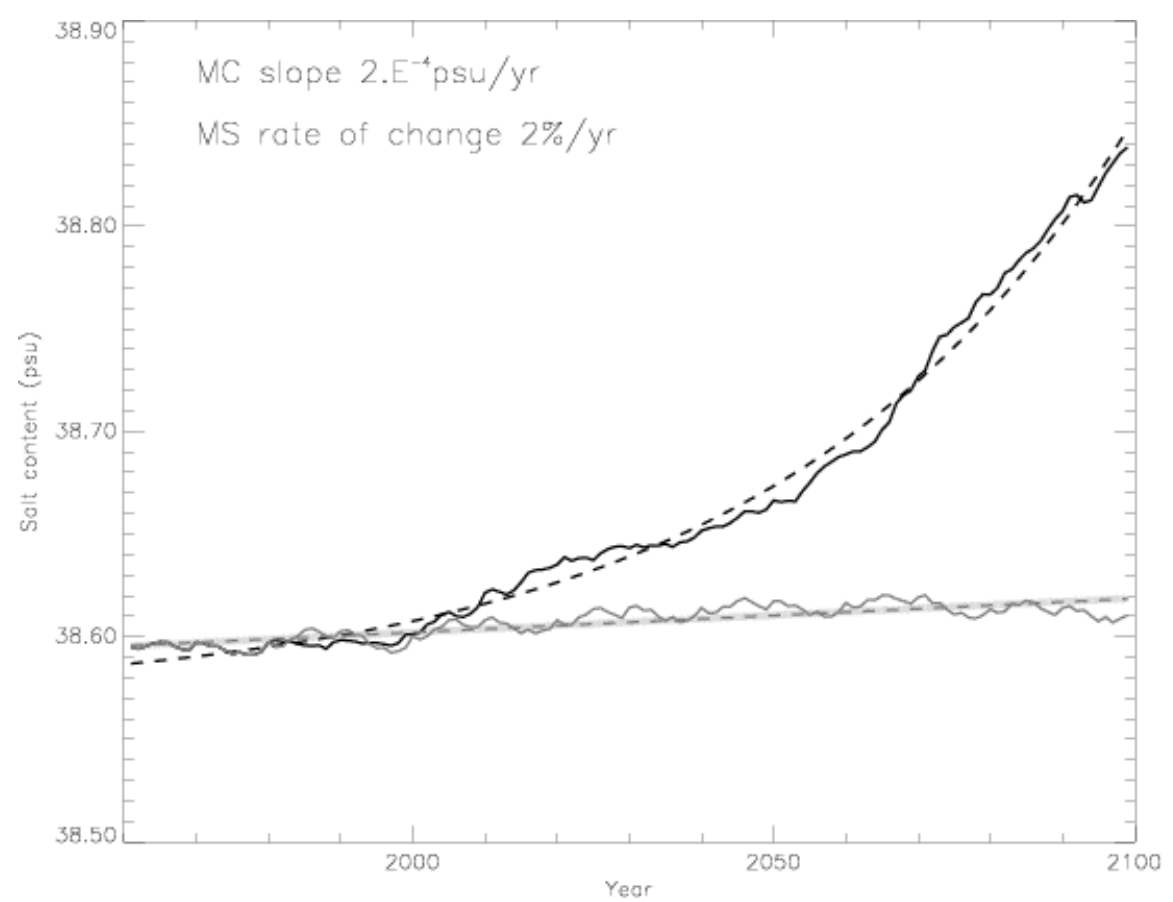

Fig. 6: As for fig. 2, but for the 3D averaged salinity, $\langle\mathrm{S}\rangle$, of the Mediterranean Sea expressed in psu 
(a)

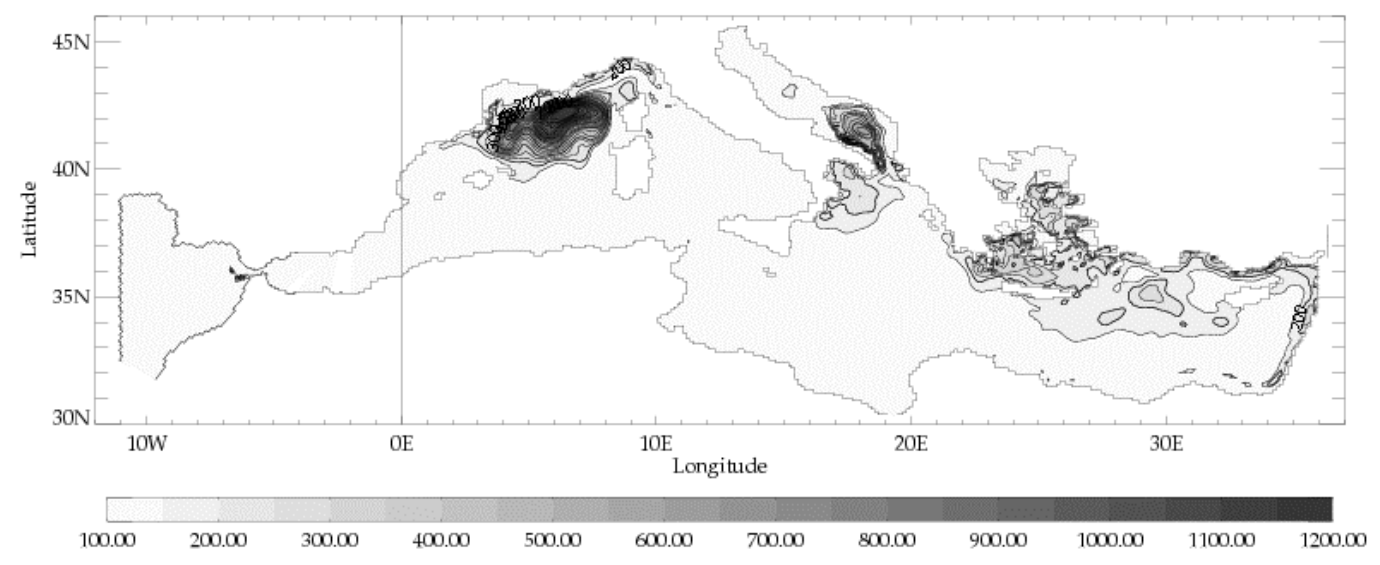

(b)

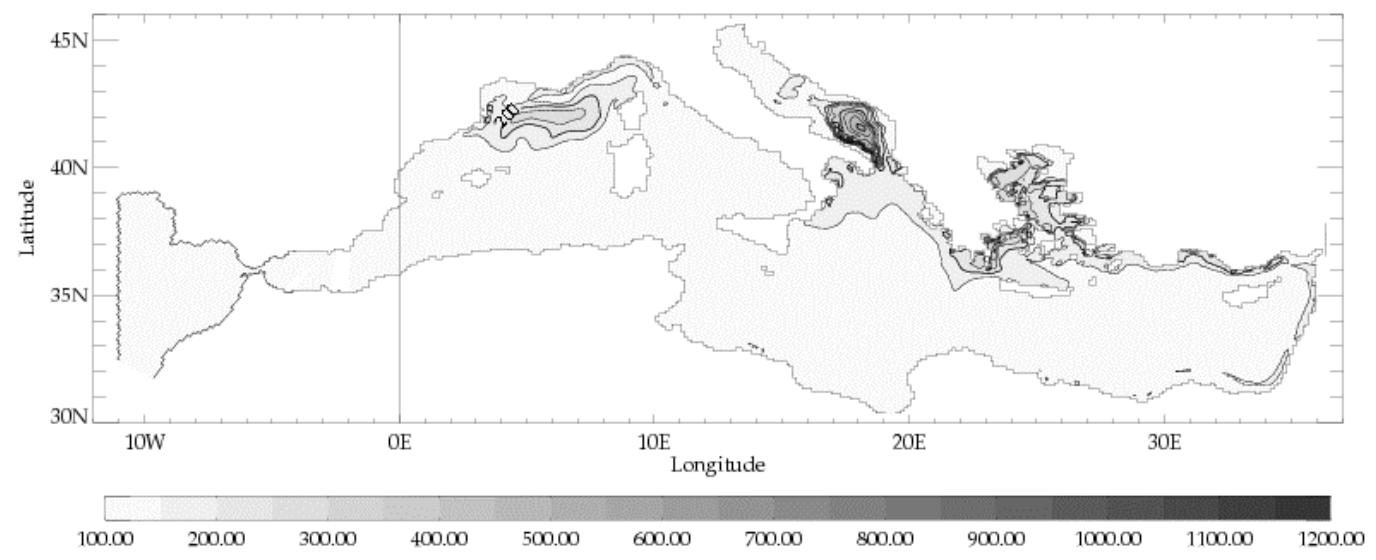

Fig 7: Mixed layer depth (in meters, interval=50m) for the winter season (JFM) averaged over the 2070-2099 period (a) for the control run (MC), and (b) for the scenario (MS) 


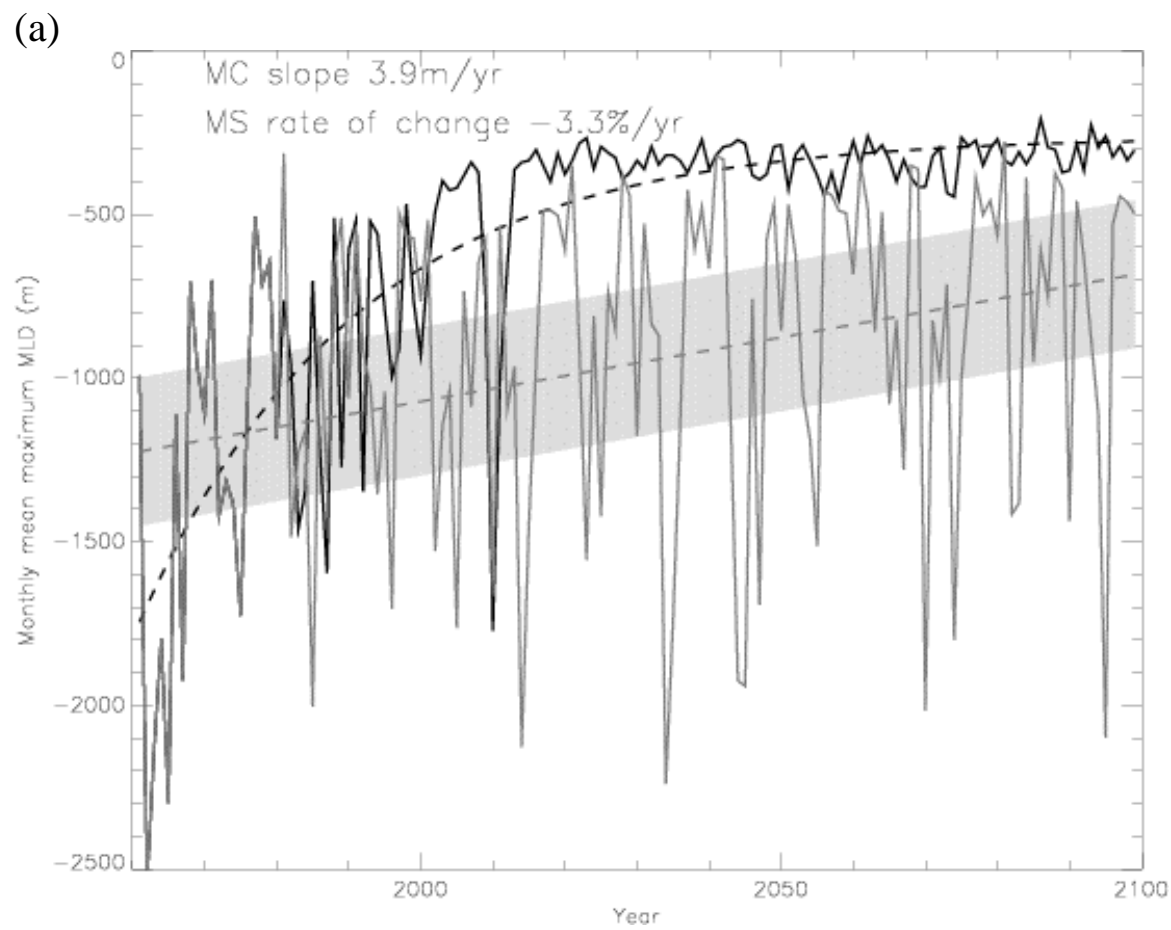

(b)

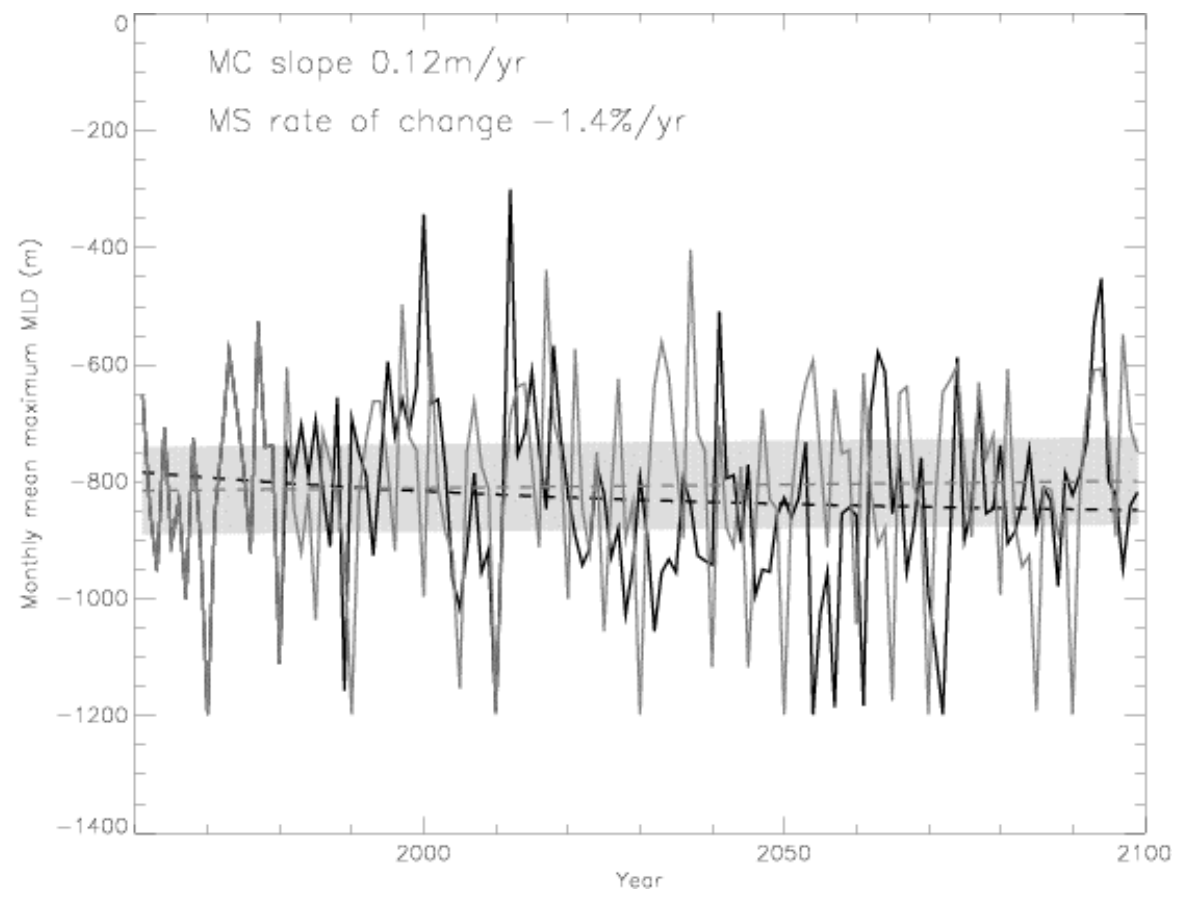

Fig 8: As for fig. 2, but for the maximum depth reached by the monthly mean mixed layer depth (1 point per year - in meters) (a) for the Levantine Basin, (b) for the Adriatic Sea, (c) for the Gulf of Lions area, and (d) for the Aegean Sea 
(c)

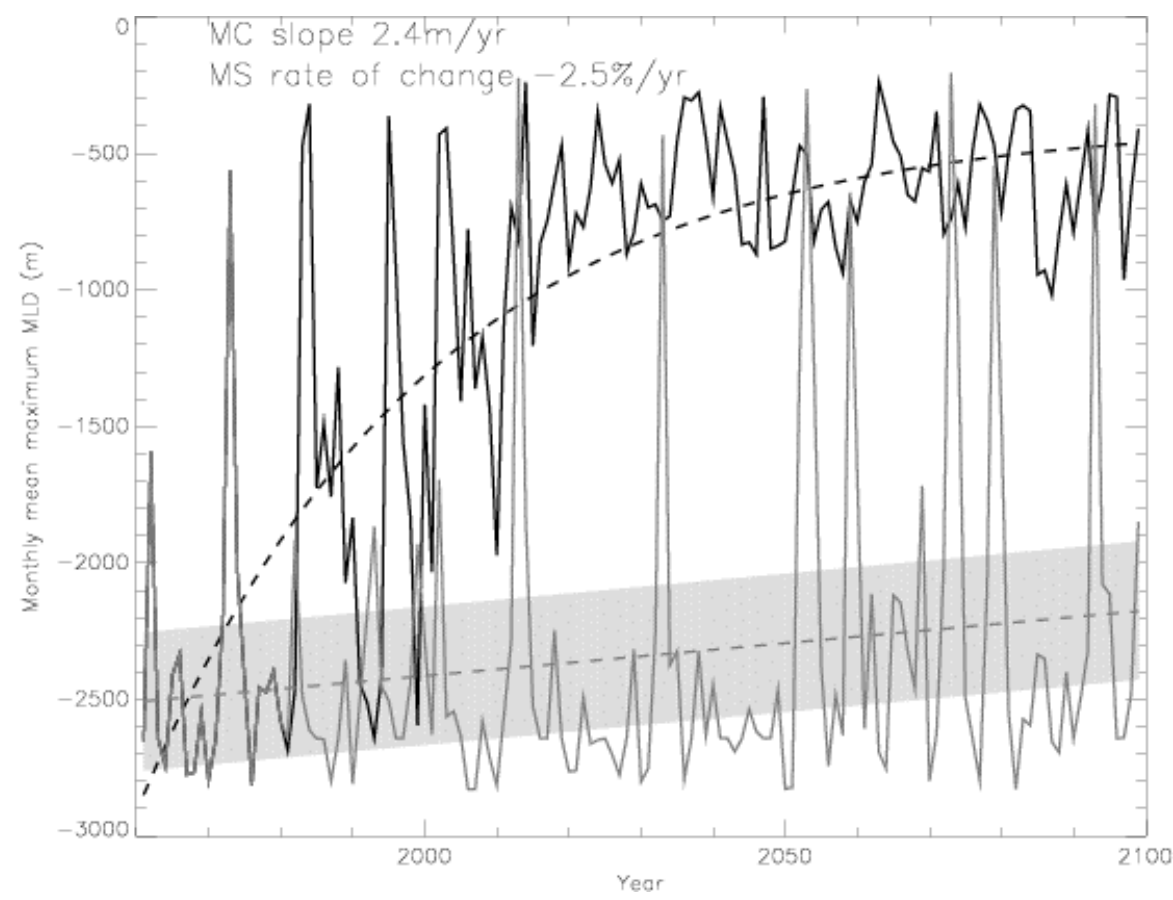

(d)

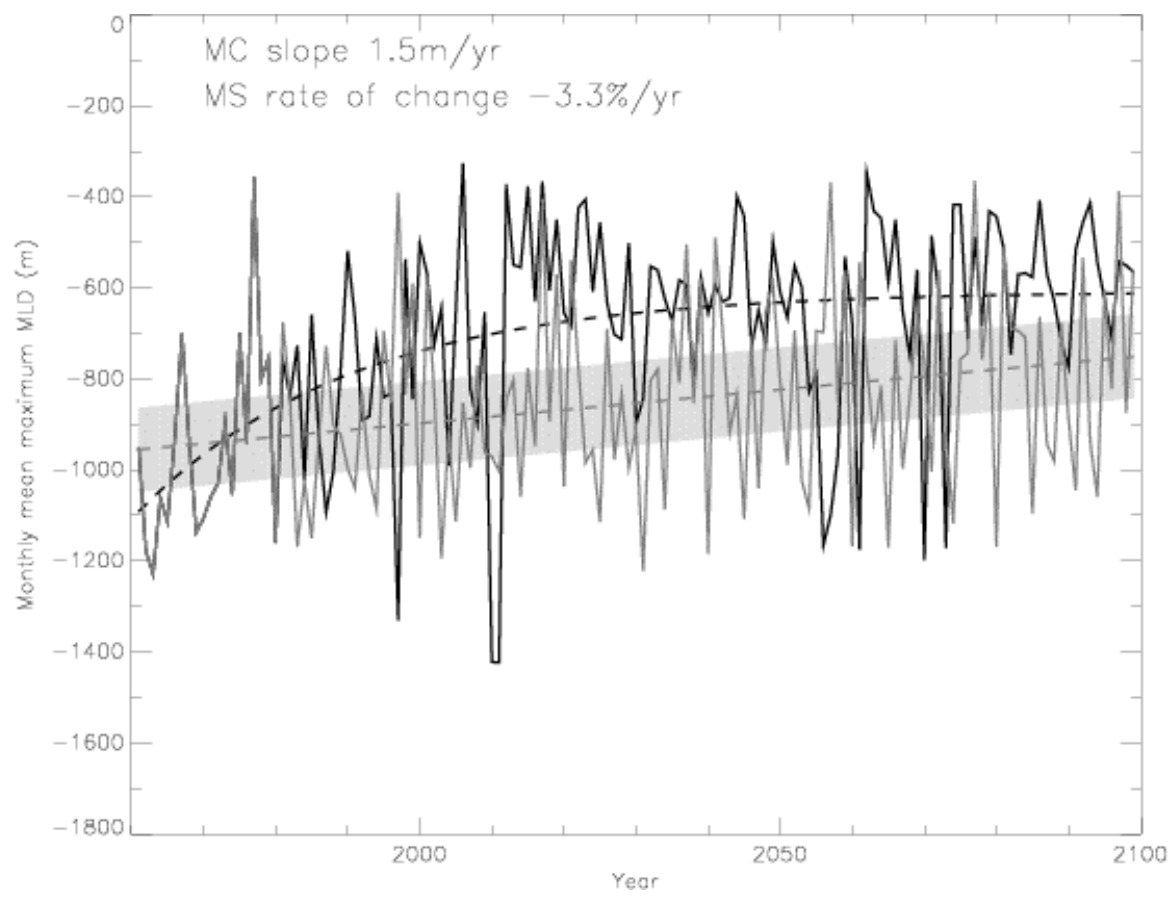

Fig 8: following 


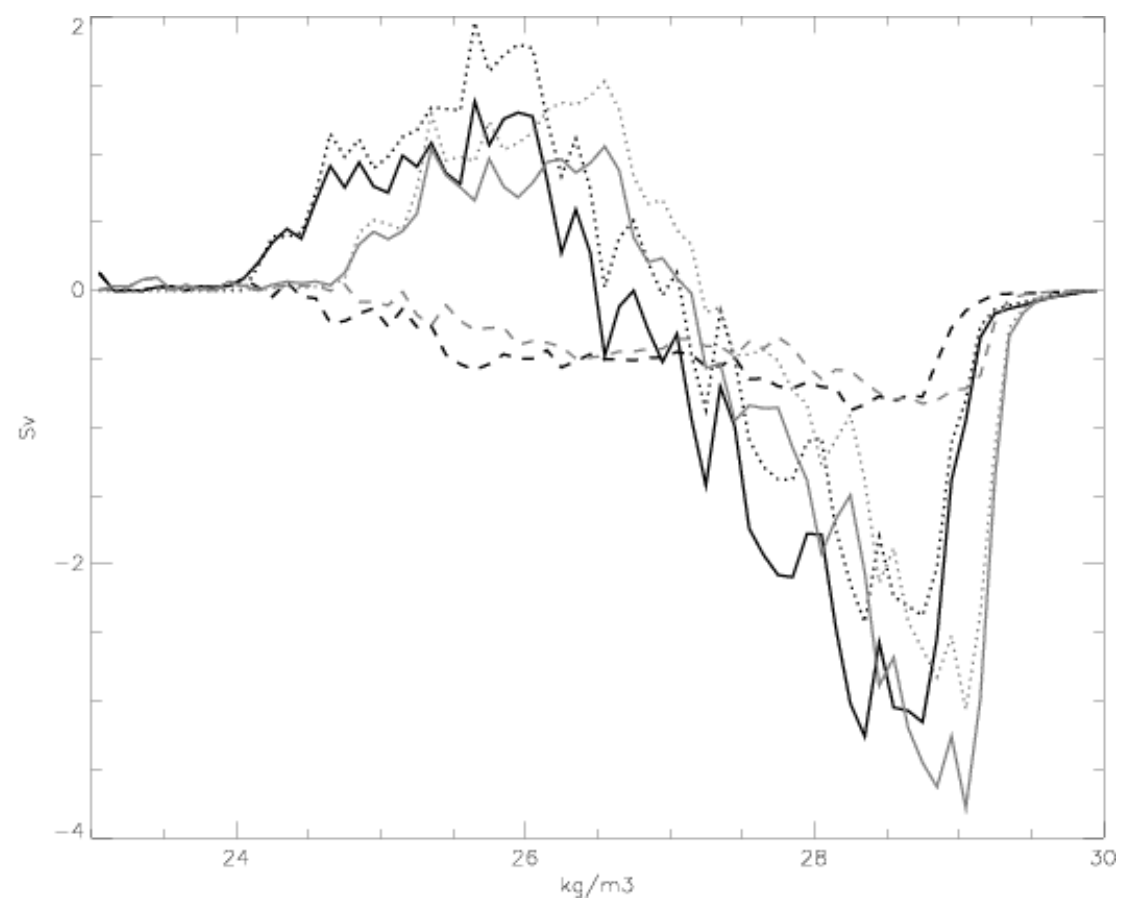

Fig 9: Water mass formation rate (in Sv) as a function of density. Values are computed for the entire Mediterranean and are averaged over the 2070-2099 period. In grey, the control run (MC) and in black, the scenario (MS). In dotted line, the heat flux contribution and in dashed line the salt flux contribution 
(a)

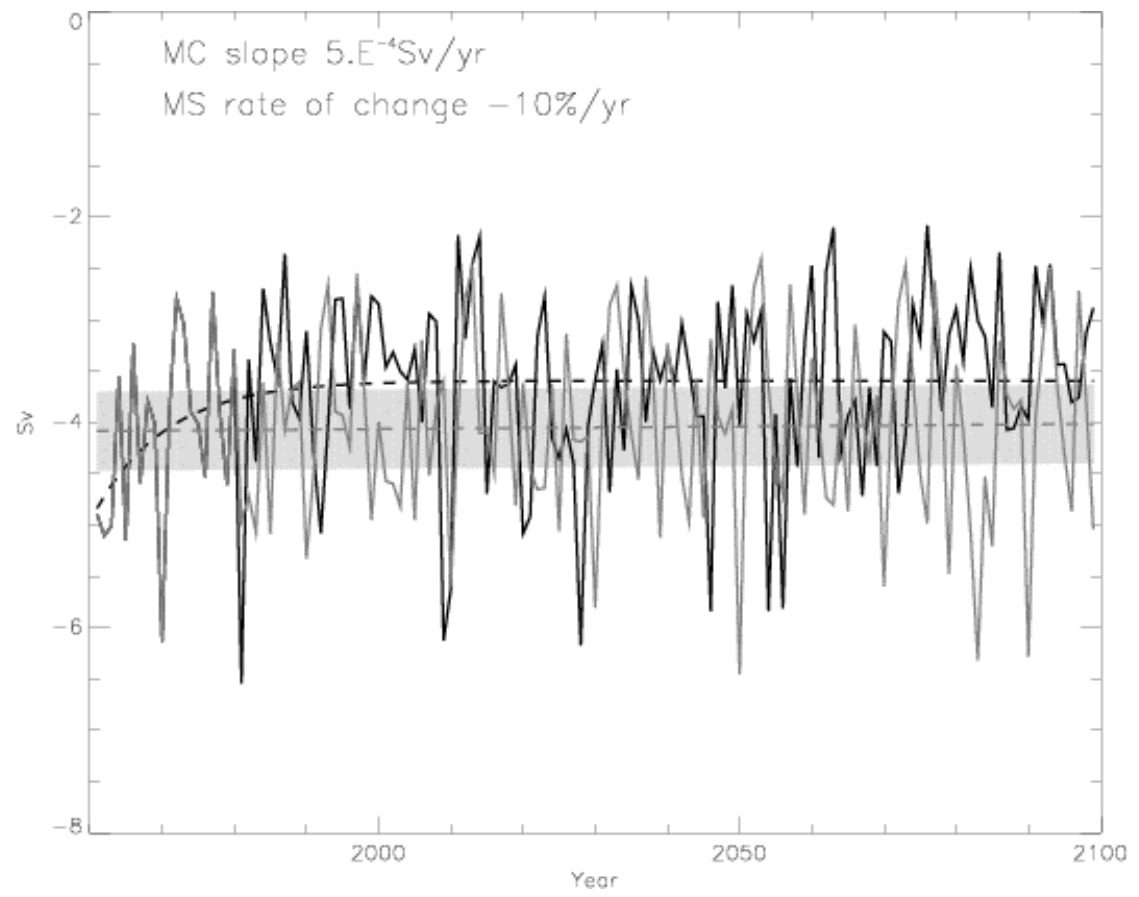

(b)

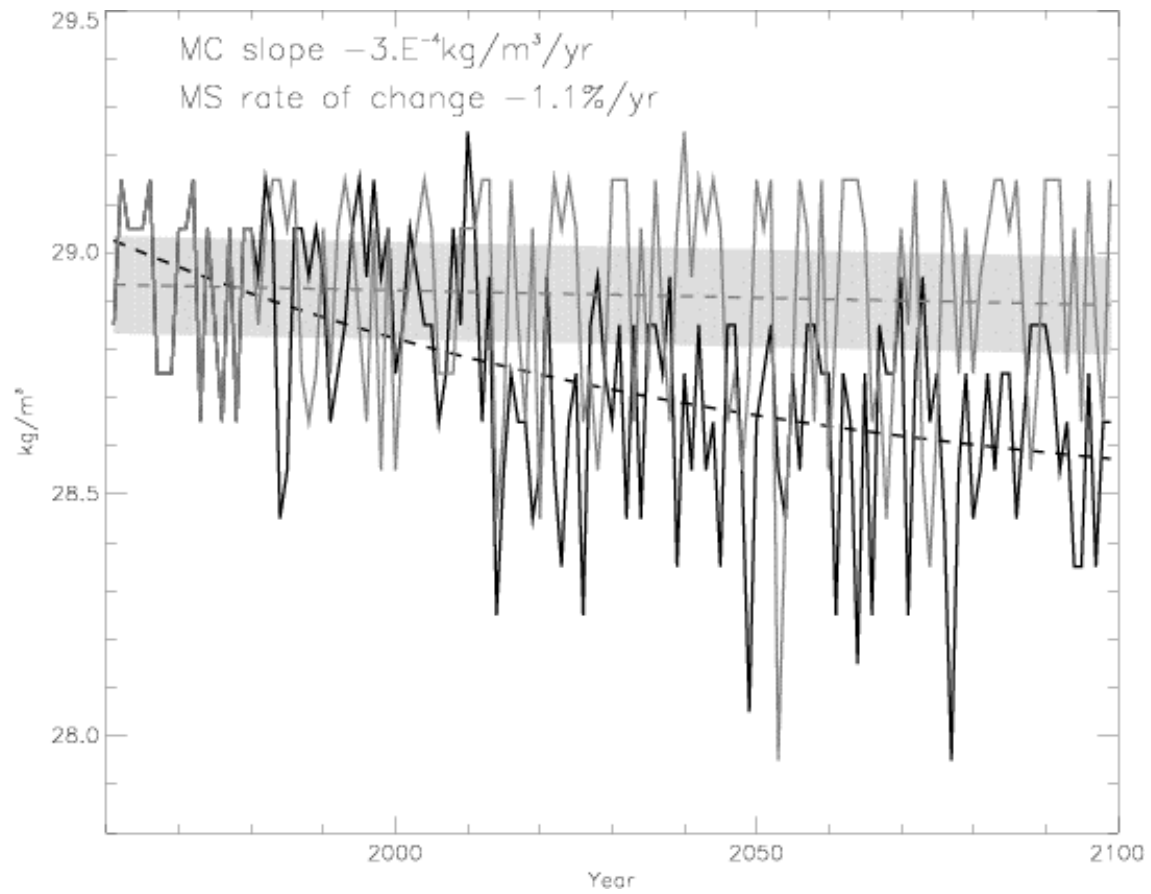

Fig 10: As for fig. 2, but for (a) the yearly maximum values of the water mass formation rate in $\mathrm{Sv}$ (this maximum formation rate corresponds to the minimum of the curve of the figure 9 computed every year for the entire Mediterranean) and (b) the density for which the maximum formation rate occurs 
(a)

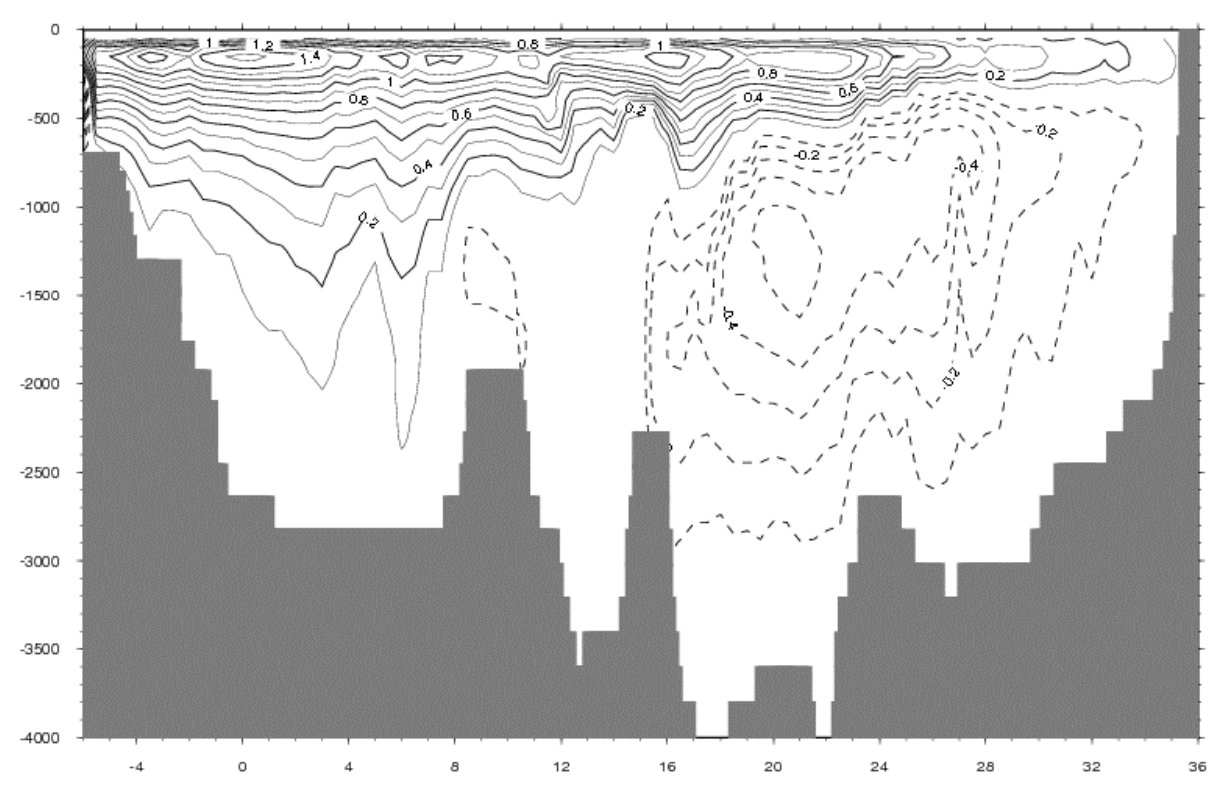

(b)

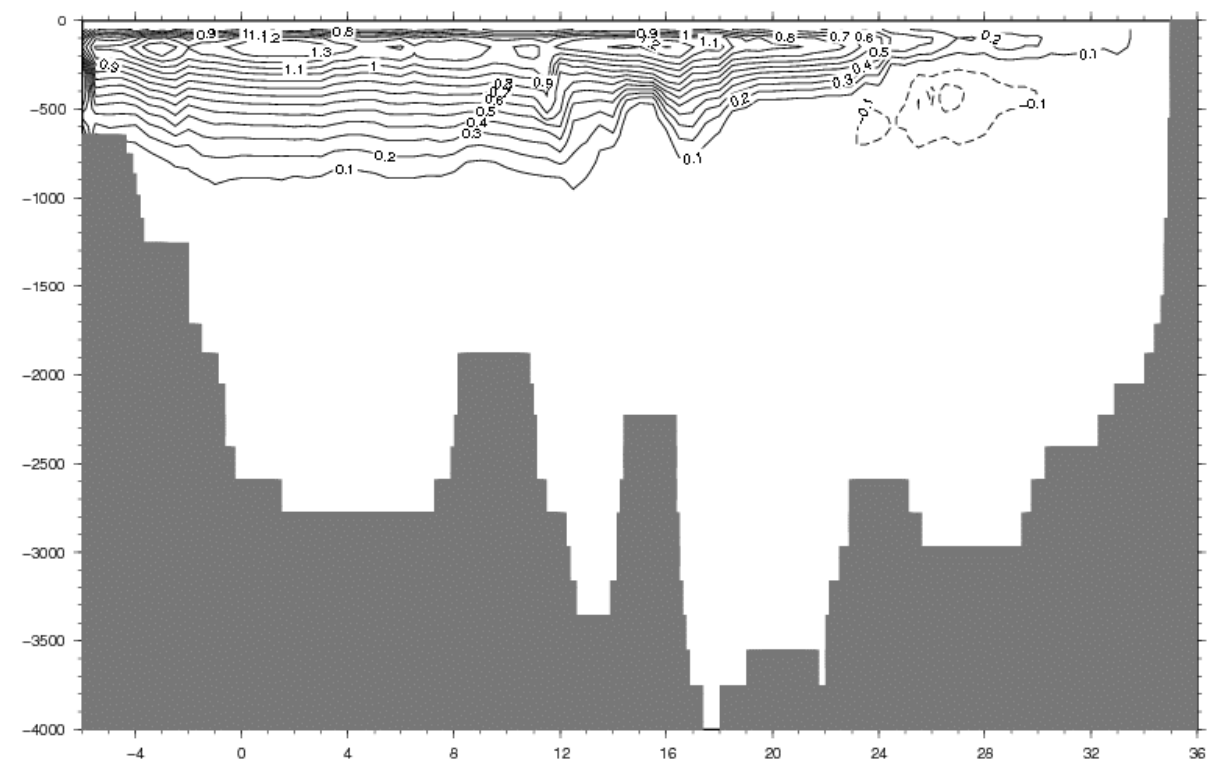

Fig 11: Vertical sections averaged over the 2070-2099 period for global Mediterranean Zonal Overturning stream Function (a) for the control run, and (b) for the scenario. The same calculation has been done for the Adriatic Meridional Overturning stream Function covering the Adriatic Sea plus the northern part of the Ionian Sea limited to $37^{\circ} \mathrm{N}$ (c) for the control run, and (d) for the scenario. The western Mediterranean Meridional Overturning stream Function limited to $38^{\circ} \mathrm{N}$ has also been computed (e) for the control run, and (f) for the scenario 
(c)

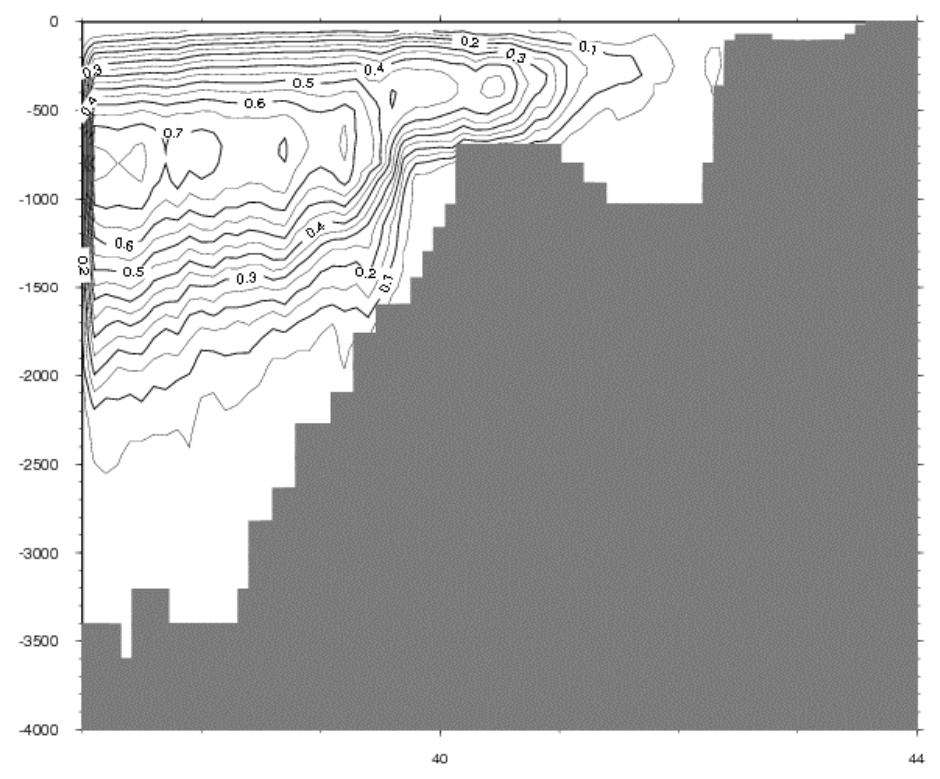

(d)

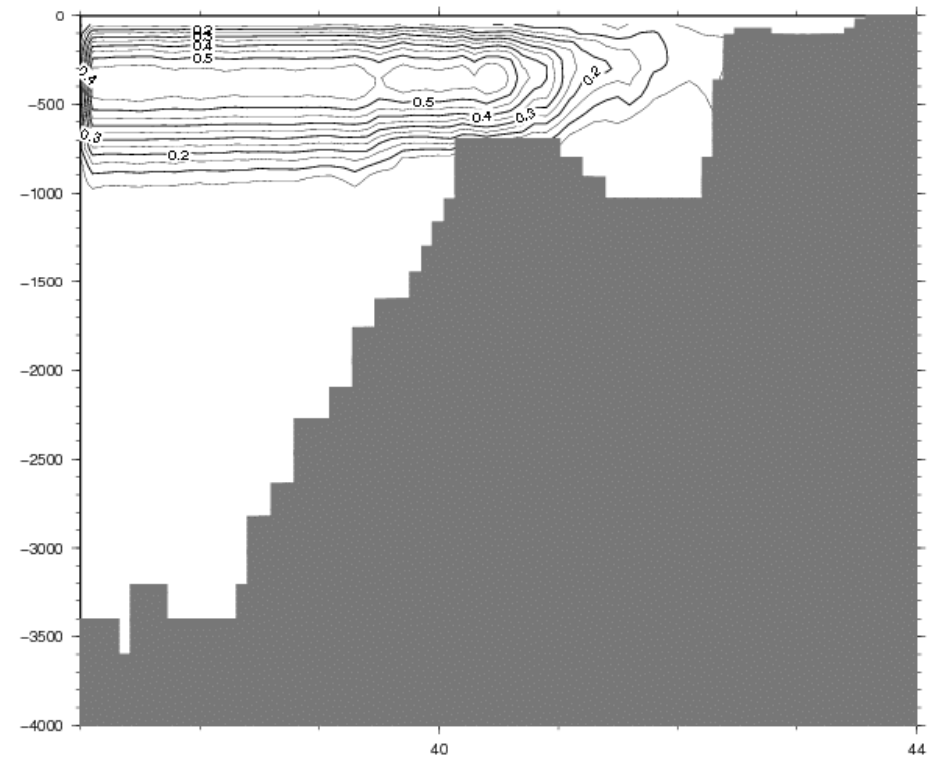

Fig 11: following 
(e)

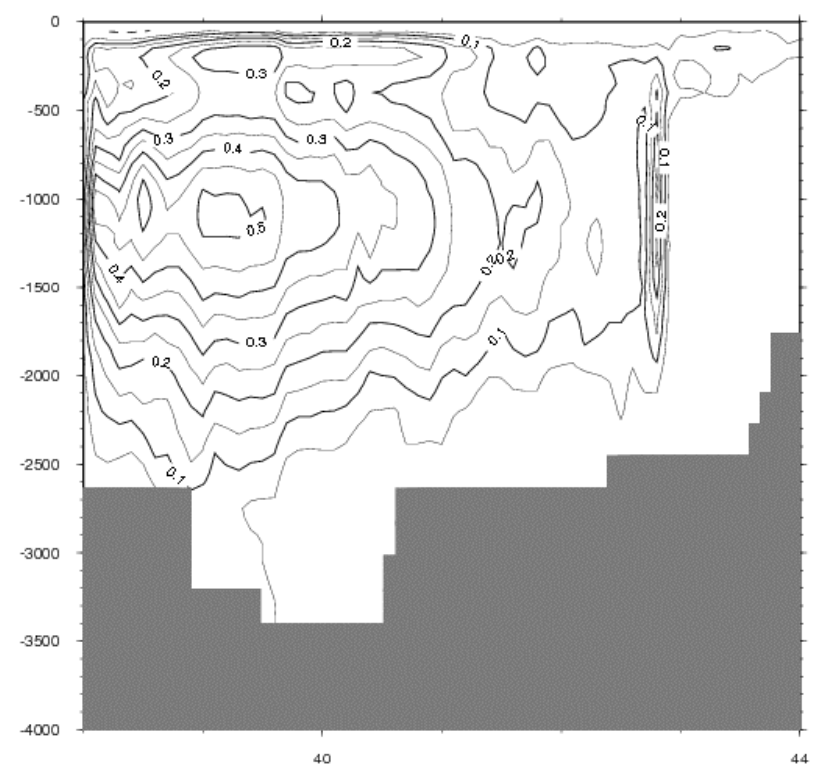

(f)

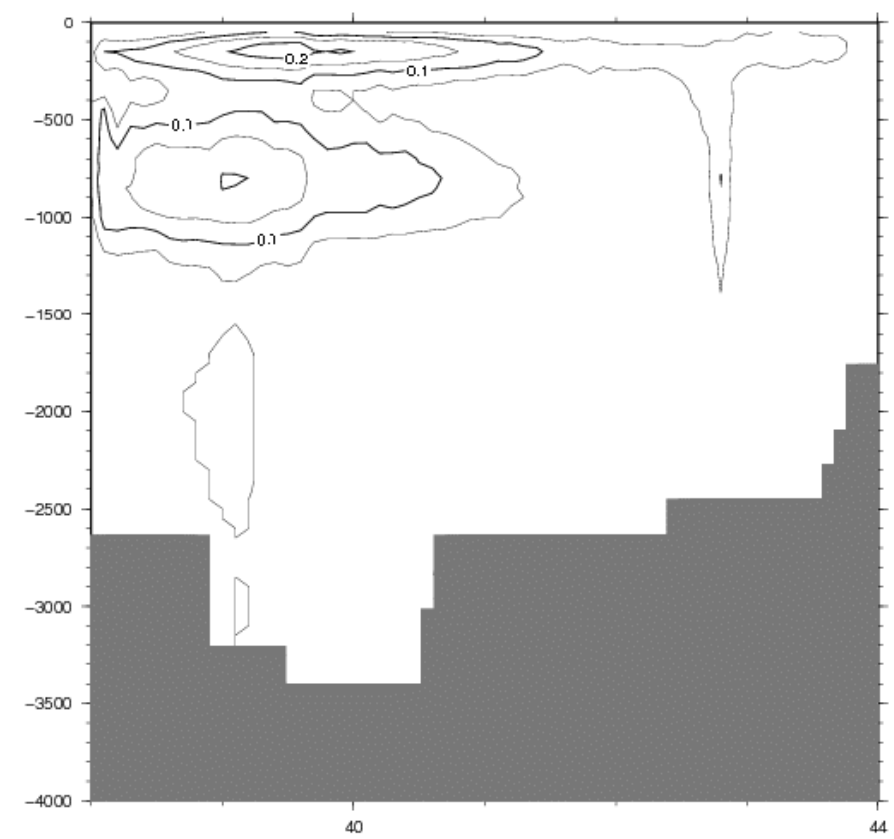

Fig 11: following 
(a)

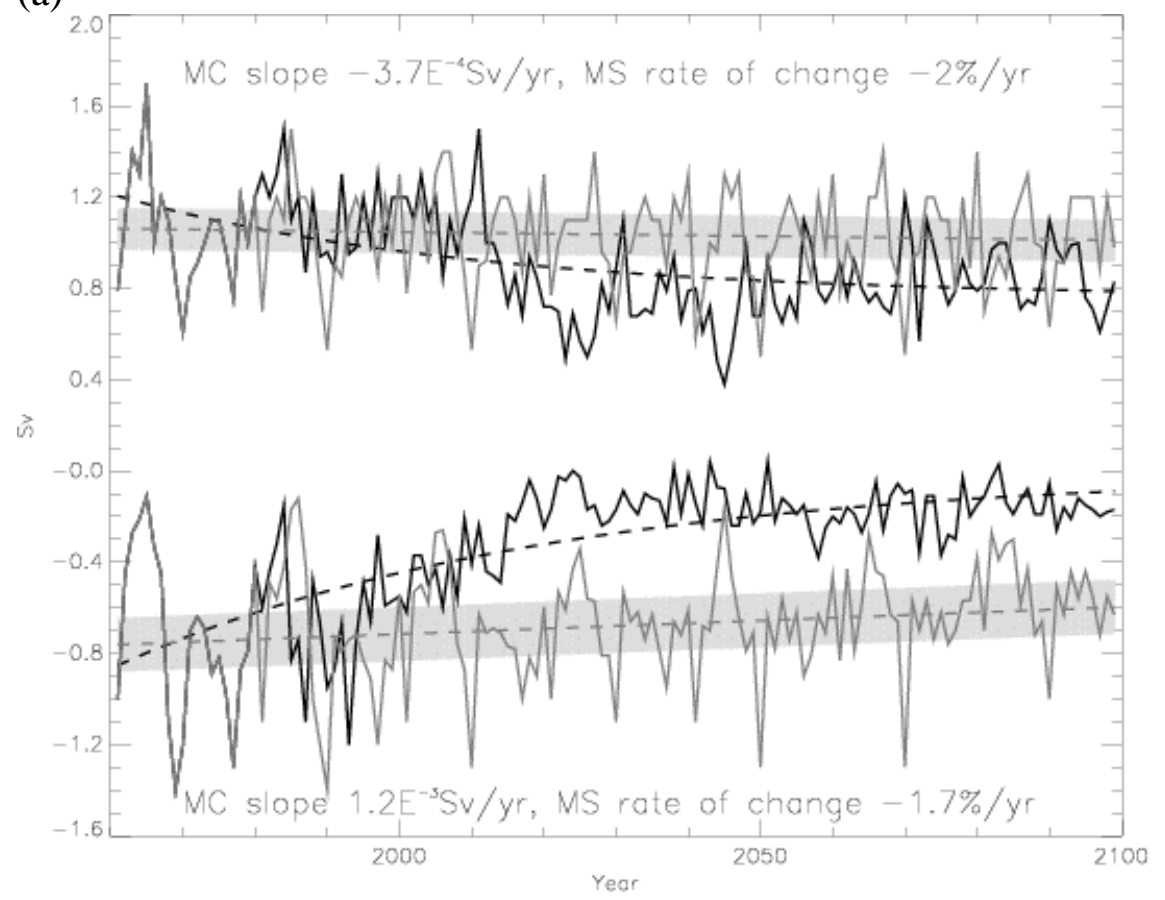

(b)

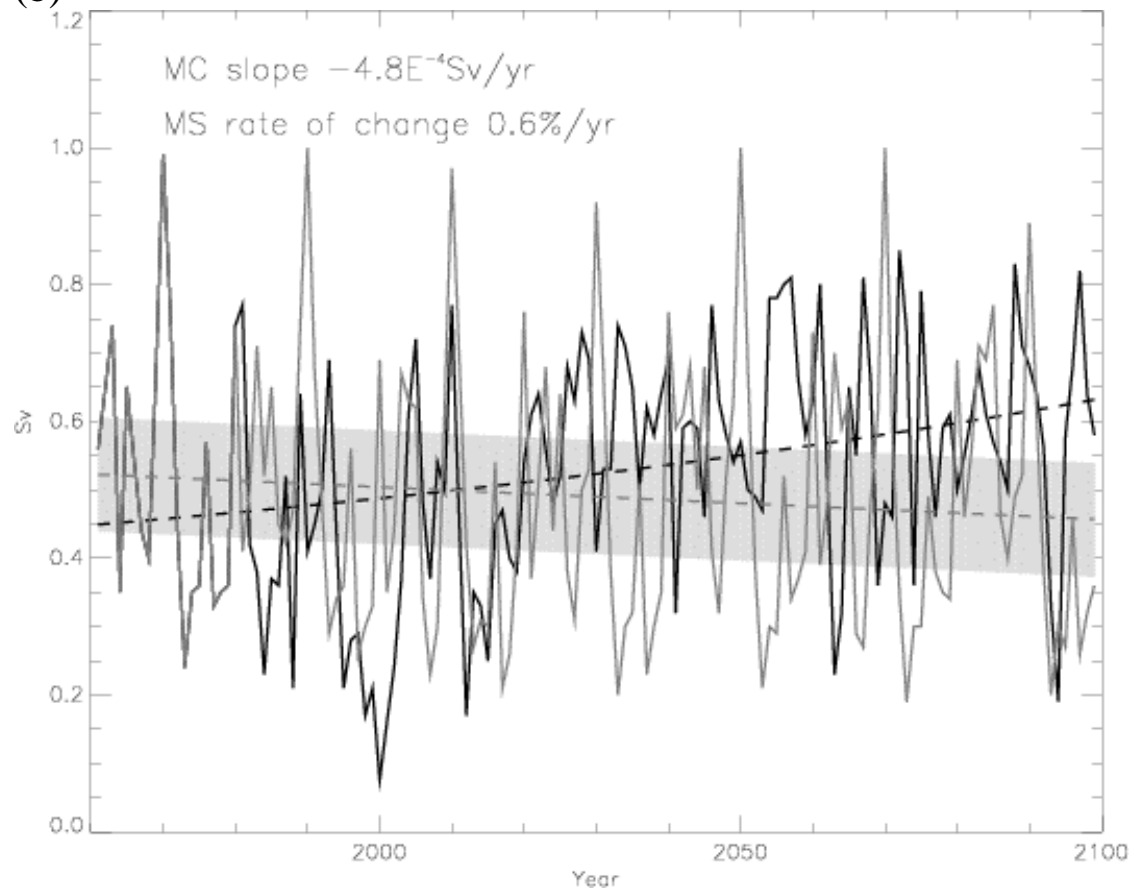

Fig 12: As for fig. 2, but for optimum values of the zonal or meridional overturning stream functions calculated for the sections defined in figure $4 a$, (a) for the section $\mathrm{F}$ at $21.7^{\circ} \mathrm{E}$ between the Ionian Sea and the Levantine Basin (the intermediate maximum and the deep minimum are plotted on the same figure), (b) for the section $\mathrm{D}$ at $40^{\circ} \mathrm{N}$ (Otranto Strait), (c) for the section $\mathrm{E}$ at $37.1^{\circ} \mathrm{N}$ (northern part of the Ionian Sea), and (d) for the sections $\mathrm{A}+\mathrm{C}$ at $40^{\circ} \mathrm{N}$ (western Mediterranean) 
(c)

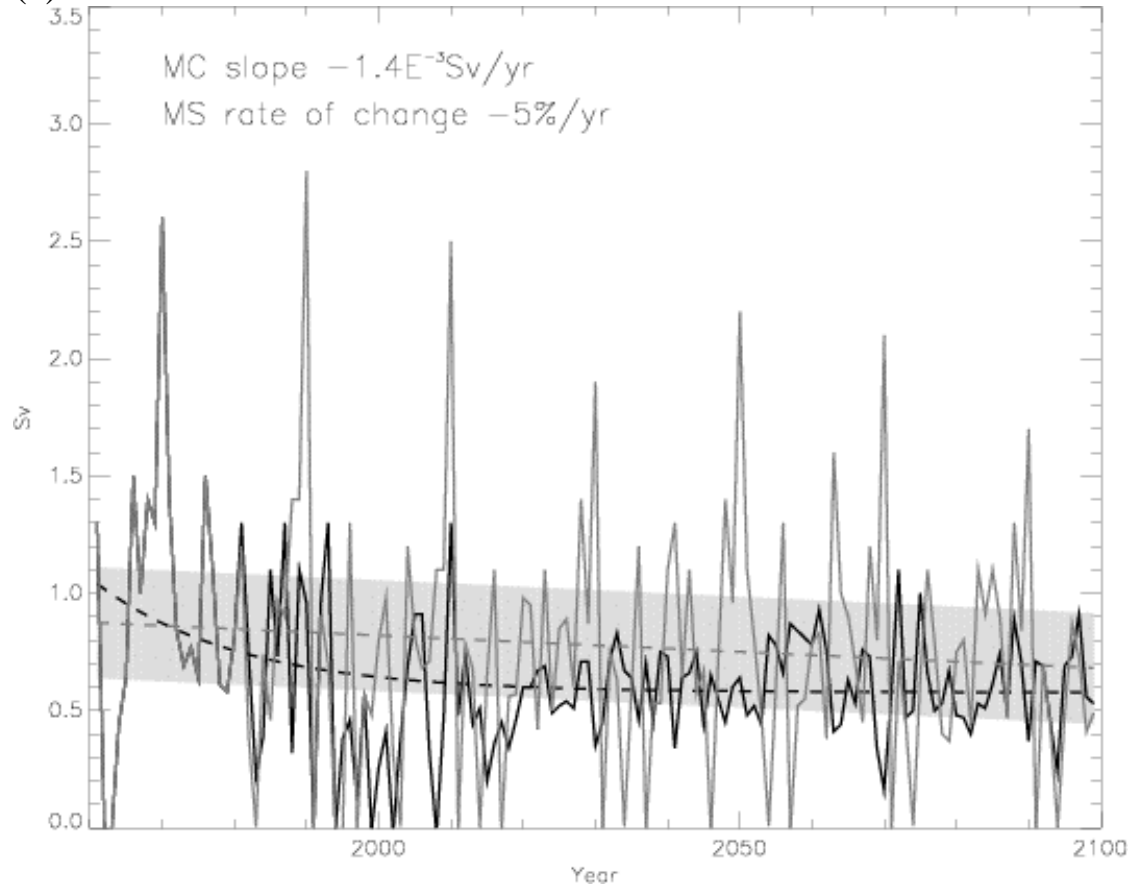

(d)

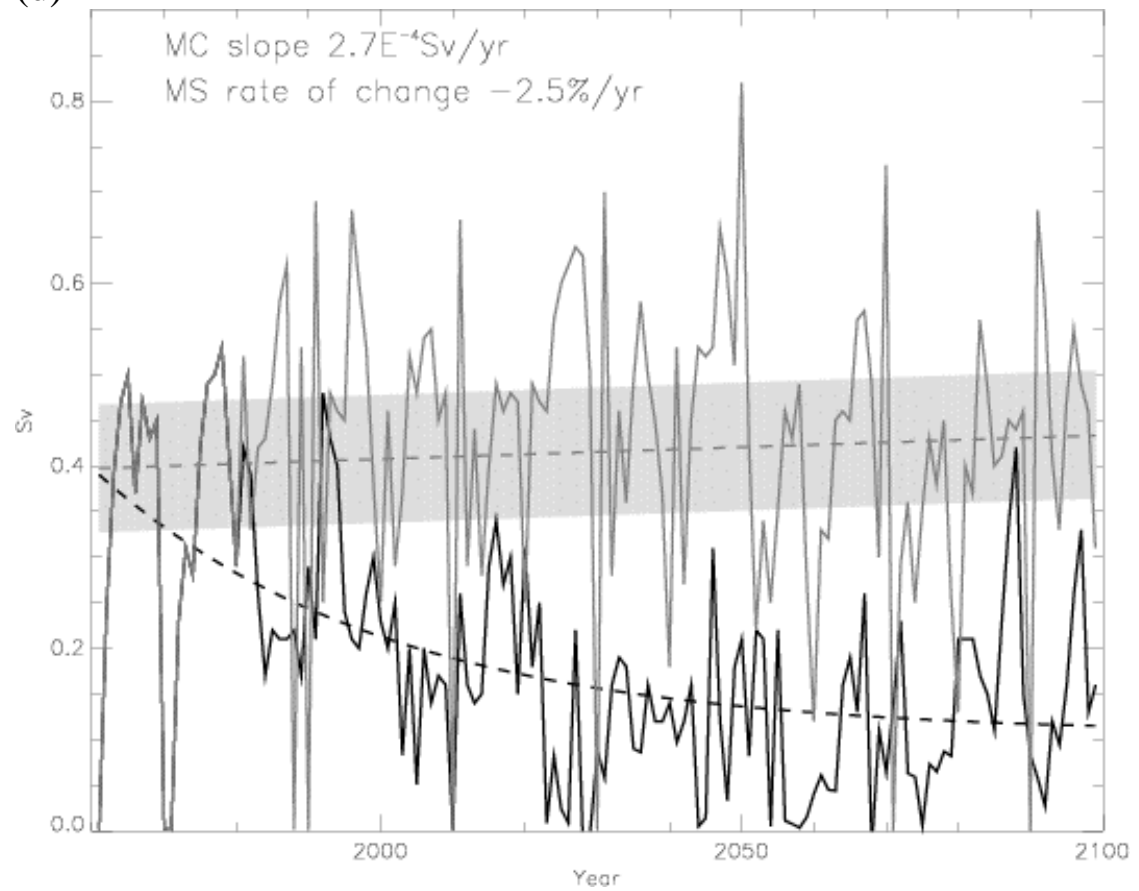

Fig 12: following 